$\begin{array}{cl}\begin{array}{cl}\text { Revue } \\ \text { de } / \text { histoire }\end{array} & \text { Revue de l'histoire des religions } \\ \text { des religions } & \begin{array}{c}4 \mid 2008 \\ \text { Varia }\end{array}\end{array}$

\title{
L'Islam vu par Carsten Niebuhr, voyageur en Orient (1761-1767)
}

Islam as seen by Carsten Niebuhr, traveller in the East (1761-1767)

\section{Michel-Pierre Detalle et Renaud Detalle}

\section{(2) OpenEdition}

Édition électronique

URL : http://journals.openedition.org/rhr/6953

DOI : 10.4000/rhr.6953

ISSN : 2105-2573

Éditeur

Armand Colin

\section{Édition imprimée}

Date de publication : 1 décembre 2008

Pagination : 487-543

ISSN : 0035-1423

\section{Référence électronique}

Michel-Pierre Detalle et Renaud Detalle, «L'Islam vu par Carsten Niebuhr, voyageur en Orient

(1761-1767) », Revue de l'histoire des religions [En ligne], 4 | 2008, mis en ligne le 01 octobre 2011, consulté le 19 avril 2019. URL : http://journals.openedition.org/rhr/6953 ; DOI : 10.4000/rhr.6953 


\section{L'Islam vu par Carsten Niebuhr, voyageur en Orient (1761-1767)}

En 1761, une expédition financée par le roi de Danemark quittait Copenhague pour le Yémen dans le but de répondre à des questions visant à éclairer certains passages de la Bible. Des six hommes qui étaient partis, un seul revint, Carsten Niebuhr, l'astronome-cartographe. À la mort de ses compagnons, il reprit la plupart de leurs tâches et publia à son retour deux ouvrages en allemand où l'Islam tient une place notable. Les éditions françaises étant anciennes et presque introuvables, il s'agit ici de mettre à la disposition des chercheurs une nouvelle traduction française des textes de Niebuhr relatifs aux religions orientales.

\section{Islam as seen by Carsten Niebuhr,} traveller in the East (1761-1767)

Funded by the king, a Danish expedition to Yemen left Copenhagen in 1761 in order to collect information intended to throw light upon certain parts of the Bible. Out of the six men who left, only Carsten Niebuhr, the astronomer-cartographer, returned. After his companions' death, he took over most of their duties and later published two books in German where Islam figures prominently. With French editions outdated and difficult to find, scholars will avail of a new French translation of Niebuhr's writings about oriental religions. 
I/ Mémorandum à l'Académie des Inscriptions et Belles-Lettres $(2 / 9 / 1768)$

II/ Beschreibung Arabiens (1772)

a) XI-XII (extrait de la préface) …............................................. 497

b) 17-18 (registres généalogiques et charges religieuses) ........... 497

c) 18-27 « Religion des Arabes » ................................................ 498

d) 40-46 «Comportement des Mahométans envers les adeptes d'autres religions »

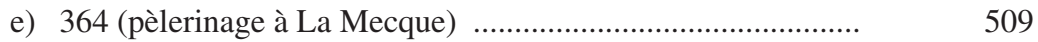

f) $377-379$ (tribus juives) ….................................................... $\quad 510$

III/ Reisebeschreibung (1774 et 1778)

a) t. I, 39-41 (traversée Constantinople-Alexandrie en septembre 1761)

b) t. I, 267-268 (port de l'ihram)

c) t. I, 438-440 (l'ermite Chadhili à Mokha)

d) t. II, 177-179 (préparatifs pour le pèlerinage à Meched Ali) .

e) t. II, 198-201 «Observations sur Kharg »

f) t. II, 254-257 «Observations sur Meched Ali » ...................... 518

g) t. II, 269-270 « Observations sur Kerbela » ........................... 520

h) t. II, 270-274 «Différence entre les Sunnites et les Chiites »

i) t. II, 274-286 «Modification de la religion des Chiites sous le gouvernement de Nadir Chah »

j) t. II, 433-438 « Religion des Druses » .................................... 533

k) t. II, 439-444 « La religion des Noussairiens » ...................... 537

1) t. II, 444 « Religion des Ismaélites » .....................................

Postface 


\section{AVANT-PROPOS}

À la demande de Johann David Michaelis (1717-1791), professeur de philosophie à l'Université de Göttingen et orientaliste, qui espérait d'une expédition en Arabia Felix des réponses à certaines interrogations découlant de la Bible, le roi de Danemark, qui finançait l'expédition projetée, avait invité les savants du monde entier à poser toutes sortes de questions sur les contrées à visiter. En France, l'Académie Royale des Inscriptions et Belles-Lettres avait dans cet esprit adressé aux savants danois un questionnaire très complet ${ }^{1}$.

Carsten Niebuhr (1733-1815, ci-après « $\mathrm{CN} »)^{2}$, Danois, chargé des observations et mesures topographiques et astronomiques, quitta Copenhague par mer en janvier 1761 avec cinq compagnons ; il y revint par terre, seul survivant, en novembre 1767. Les autres membres de l'expédition étaient un philologue (von Haven, 1727-1763, Danois, docteur en théologie et arabisant), un naturaliste (Forskaal, 1732-1763, Suédois, botaniste, qui avait été élève de Linné, également arabisant), un médecin (Cramer, 1732-1764, Danois, chargé de la santé des participants, éventuellement de celle des tiers rencontrés), un dessinateur (Baurenfeind, 1728-1763, Allemand, peintre), et un domestique, ancien dragon (Berggren, Suédois, ?-1763). Le groupe, arrivé à Constantinople par mer, en repartira de la même manière vers l'Égypte, et de là gagnera le Sinaï, le Yémen, Oman, Bombay, où le dernier compagnon de voyage décédera ; le retour de $\mathrm{CN}$ seul se fera par Mascate, la Perse, l'Irak, la Syrie, la Turquie et les Balkans.

Or $\mathrm{CN}$, qui avait dû retourner à la terre à 16 ans après le décès de son père, avait à 22 ans, ayant touché sa part d'héritage, choisi, en vue d'une carrière de géomètre, d'aller au lycée pour pouvoir entrer à l'Université, ce qu'il fit à 24 ans seulement, en 1757. Ses deux compagnons scientifiques ayant reçu en prévision du voyage le titre de professeur, ce même titre fut

1. Michaelis, qui l'avait publié en allemand à Francfort/Main en 1762, le publiera en la même ville en 1763 sous le titre Recueil des questions proposées à une société de savants qui par ordre de Sa Majesté Danoise font le voyage de l'Arabie. Cf. Histoire de l'Académie des Inscriptions et Belles-Lettres 28, Paris 1764, 1-30.

2. Sur CN, $c f$. la biographie écrite par son fils Barthold Georg Niebuhr (1776-1831, haut-fonctionnaire puis professeur à Berlin et à Bonn, auteur d'une célèbre Histoire romaine) : Carsten Niebuhrs Leben, dans Kleine historische und philosophische Schriften, Bonn 1828, 12 (1 ${ }^{\text {re }}$ éd. 1816) ; voir surtout Josef Wiesehöfer/Stephan Conermann (dir.), Carsten Niebuhr und seine Zeit, Stuttgart 2002, notamment les éléments biographiques 17- 46, ainsi que L.F. Alfred Maury, L'ancienne Académie des Inscriptions et Belles-Lettres, Paris 1864, 378-379, et notre article sur les rapports entre l'expédition, Niebuhr et la France : «Die dänische Expedition nach Arabien, C. Niebuhr und Frankreich », dans HMRG (Historische Mitteilungen der Ranke-Gesellschaft), 16/2003, 1-14. 
offert à $\mathrm{CN}$ : il le refusa par modestie et reçut celui de lieutenant au corps des ingénieurs. Cette attitude, ainsi que le fait qu'il avait payé de ses deniers les instruments nécessaires aux observations, conduisirent le chancelier de Danemark, Bernstorff, à lui confier la caisse de l'expédition, au grand dam du philologue qui se considérait comme le chef naturel de celle-ci ${ }^{3}$ : n'avaitil pas été désigné le premier, n'était-il pas le plus âgé, n'avait-il pas étudié l'arabe, les questions religieuses n'étaient-elles pas primordiales ? Tout cela importe peu puisque le philologue décédera au Yémen en 1763, suivi de près par le naturaliste ; le dessinateur et le domestique trouveront la mort au cours de la traversée du Yémen à Bombay, où mourra le médecin (il semble qu'ils soient tous décédés d'une forme aiguë de malaria, à laquelle $\mathrm{CN}$ n'aurait échappé, de justesse selon son récit, qu'en adoptant entièrement les habitudes alimentaires des pays traversés).

Dès que, en 1758, sa participation au voyage fut acquise, $\mathrm{CN}$ suivit des cours d'arabe, et on peut penser, sachant qu'il était un grand travailleur avide de connaissances ${ }^{4}$, qu'il disposait à son départ des bases en cette langue, mais théoriques seulement, car Michaelis ne cachait pas n'avoir aucune connaissance de la langue parlée. En dehors de cela, $\mathrm{CN}$ faisait des mathématiques et acquérait les connaissances et les techniques qui lui permettraient d'effectuer les travaux de topographie, de cartographie et d'astronomie dont il serait chargé. On notera donc que CN n'aura disposé que de trois ans d'Université pour ce faire, et on ne pourra qu'admirer la manière dont cet homme saura s'acquitter de ses tâches puis assumer en sus une grande part de celles de ses compagnons après leur disparition.

Le compte rendu de l'expédition se trouve dans les deux ouvrages de $\mathrm{CN}$ : le premier, Beschreibung von Arabien («Description de l'Arabie », ci-après «Beschr. Arab. »), un volume publié à Copenhague en 1772 (édition anastatique, Graz 1969) ; le second, Reisebeschreibung nach Arabien und anderen umliegenden Ländern ( "Description d'un voyage en Arabie et autres pays circonvoisins », ci-après «Reisebeschr. »), trois volumes, dont les deux premiers ont été publiés à Copenhague en 1774 et 1778, le troisième, posthume, à Hambourg en 1837 (édition anastatique de l'ensemble, Graz 1968) ${ }^{5}$. On

3. Alors que la première phrase de l'art. 6 des instructions royales est formelle : «Les savants voyageurs sont parfaitement égaux entre eux, et aucun ne pourra, sous quelque prétexte que ce soit, s'arroger quelque autorité ou supériorité sur les autres ».

4. B. G. Niebuhr, op. cit., 12, parle de son « appétit illimité de connaissances ». On trouvera également quelques notations sur $\mathrm{CN}$ dans le livre consacré à son fils par Gerrit Walther, Niebuhrs Forschung, Stuttgart 1993.

5. Le tome III est consacré à la fin du voyage (Alep-Copenhague) et complété par les observations astronomiques de Niebuhr ainsi que des annexes diverses, les plus importantes étant consacrées à Persépolis, au temple de Jérusalem, à la détermination des lieux évoqués par Xénophon dans les campagnes de Cyrus, à l'Abyssinie. 
notera que ces ouvrages sont écrits en langue allemande, celle qui était parlée en Schleswig et Holstein, où Niebuhr a passé la plus grande partie de sa vie ; ces deux duchés relevaient alors de la Couronne danoise 6 . Alors qu'il avait voulu être son propre éditeur, opération qui avait été financièrement catastrophique, il récidiva en confiant la traduction française à un « clerc réfugié » : le résultat fut également mauvais sur le plan financier, mais aussi sur le plan linguistique. La traduction officielle de Besch. Arab., Copenhague 1773, fut suivie d'une autre, illégale celle-là (Amsterdam 1776), celle de Reisebeschr. (2. vol.) parut en 1776 et 1778 à Copenhague toujours ; à notre connaissance, la dernière traduction française de Beschr. Arab., revue et corrigée par Joseph de Guignes, membre de l'Académie Royale des Inscriptions et Belles-Lettres, parut à Paris en $1779^{7}$.

Alors que le second ouvrage est un récit chronologique du départ à Alep, le premier, thématique, se divise en deux parties : la première traite des frontières, du climat, des mœurs, de l'agriculture, etc., tandis que la seconde décrit les différentes régions du Yémen, ce pays étant en effet la destination officielle de l'expédition. Et c'est évidemment dans la première partie du premier ouvrage, Beschr. Arab., que se trouve le chapitre consacré à la « religion des Arabes ». Par une cocasserie et une méchanceté de l'histoire, $\mathrm{CN}$, auquel on avait donné un titre militaire lié aux divers travaux de mesures physiques dont il était chargé et qui a accompli sur ce plan de véritables exploits, n'a été réellement reconnu de son vivant que pour ses relevés de monuments et d'inscriptions, notamment à Persépolis, ainsi que pour ses récits généraux et ses très nombreuses observations sur la langue arabe. Au Danemark même, où, à son retour, les conditions politiques avaient beaucoup changé, Niebuhr ne bénéficia guère, outre la pension promise, que d'une promotion au grade de capitaine, et de la prise en charge par la Couronne des cuivres des planches et cartes. Ayant écrit plus tard à la rédaction d'une revue publiée par un astronome à la cour de Saxe, CN fut incité par ce dernier à écrire des articles, c'est ainsi que furent connues pour la première fois certaines de ses observations astronomiques.

Ce qu'on sait moins, ou ce qu'on ne sait pas car le document avait disparu, c'est que CN avait adressé à l'Académie dès septembre 1768, soit dix mois après son retour à Copenhague, un mémorandum en latin de

6. Laquelle régnait également à cette époque sur la Norvège, qui tombera sous la coupe de la Suède en 1814 et ne deviendra indépendante qu'en 1905.

7. Selon nos recherches, il n'y aurait d'autre traduction française des deux premiers volumes de Reisebeschr. que celle parue en Suisse (lieu non précisé) en 1780, que nous n'avons pu consulter. CN s'est en outre chargé de la publication des travaux de Forskaal sur la faune et la flore (descriptions et planches), trois grands volumes publiés, les deux premiers en 1775, le dernier en 1776, tous à Copenhague. 
10 feuilles recto-verso, dans lequel il donnait ses premières réponses et annonçait des travaux postérieurs ${ }^{8}$.

Devant une réalité, qui est l'ignorance de $\mathrm{CN}$ et de son œuvre chez de nombreux auteurs de notre temps ${ }^{9}$, le présent travail se propose de mettre à la disposition des chercheurs à la fois une traduction française du passage consacré à la religion dans le mémorandum en latin et une nouvelle version en français des divers écrits de $\mathrm{CN}$ relatifs au même thème : cela devrait permettre, à partir des notations d'un observateur particulièrement scrupuleux, un réexamen des connaissances sur l'Islam et ses différentes composantes dans la seconde moitié du XVIII ${ }^{\mathrm{e}}$ siècle.

Pour ce travail, les conventions suivantes s'appliquent :

- Bien qu'elles ne semblent pas toujours logiques, les ponctuations des textes originaux sont respectées (ainsi que les soulignements dans le mémorandum).

- CN utilise constamment le mot «Mahométans » (mot forgé par les Européens et jamais utilisé par les intéressés) mais exceptionnellement le terme « Musulmans », qu'il définit Rechtgläubige, « croyants respectant le dogme » (ce qui correspond au sens du mot arabe « ceux qui se soumettent », cf. inf.) : nous ne pouvons donc que conserver le mot «Mahométans » partout où il se trouve.

- La majuscule est utilisée au début des noms d'adeptes de religions (un Juif, un Druse), de nationaux (un Hollandais, un Européen), et des titres de dignitaires civils, religieux ou militaires s'ils sont liés à un nom de personnage (Chérif Mesaad ou Nadir Chah) ; une exception toutefois : « Imam » seul avec majuscule désigne le souverain du Yémen.

8. Inexploité à l'Académie et volé vers 1830 avec des centaines d'autres documents et ouvrages dans diverses institutions françaises (tous rachetés à la fin du siècle par la Bibliothèque nationale), M.-P. Detalle, qui l'a redécouvert (voir son article cité supra note 2), se propose d'en donner une traduction intégrale.

9. Exemples : absence de toute mention chez Edward W. Said, Orientalism, New-York 2003, chez Albert Hourani, A history of the Arab people, New-York 1992, chez Serge Moussa, Le voyage en Égypte. Anthologie des voyageurs européens de Bonaparte à l'occupation anglaise, Paris, Bouquins, 2004 (ce dernier auteur se réfère entre autres à des voyageurs du XVI ${ }^{\mathrm{e}}$ siècle ainsi qu'à Pococke et Norden, qui ont précédé de peu Niebuhr, tous étant antérieurs à Bonaparte !) ; le catalogue de l'exposition Voyages en Égypte de l'Antiquité au XX $X^{e}$ s., Genève 2003, oublie également CN, alors que le premier volume de Reisebeschr. contient une trentaine de planches sur l'Égypte, dont un plan du Caire, une carte du delta qui fait défaut chez Norden, etc. Le fait que CN écrive en allemand explique-t-il cette situation ? Outre la traduction française, il existe une traduction anglaise, et le catalogue de la British Library mentionne une publication en arabe de 1965 dont le titre, il est vrai, se lit Le voyage de Niebuhr en Iraq [sic] au $18^{e}$ s. 
- L'astérisque «* * avant ou après un mot indique qu'une graphie arabe précède ou suit ce mot dans le texte original de $\mathrm{CN}$.

- Les mots d'origine étrangère, sauf s'ils sont très courants (imam, cheikh, etc.), ainsi que les références bibliographiques dans le texte de $\mathrm{CN}$ et dans les notes sont en italique.

- Les toponymes et anthroponymes sont, autant que faire se peut, transcrits selon une graphie moderne, étant entendu que le « Mohammed » de CN sera, suivant l'usage français, « Mahomet » s'il s'agit du Prophète, «Mohammad», plus proche de l'arabe, dans les autres cas.

- Les notes de CN, pour autant qu'elles se rapportent directement à la religion, sont introduites dans le corps du texte comme suit : «[n. ...]».

- Toutes les notes de bas de page émanent des auteurs de cette contribution ${ }^{10}$ : elles sont indicatives et restent très en deçà d'un commentaire exhaustif d'écrits d'une grande richesse.

10. Les deux auteurs, qui gardent l'exclusive responsabilité de leur travail, adressent leurs vifs remerciements à $\mathrm{M}^{\mathrm{me}}$ Lucette Valensi (École des Hautes Études en Sciences sociales), qui a suscité et soutenu cette contribution, à M. Bernard Haykel (université de Princeton) pour ses suggestions concernant les notes, à M. Lahcen Daaif (École pratique des Haute Études, Sciences religieuses) pour sa lecture attentive. 


\section{MÉMORANDUM À L'ACADÉMIE DES INSCRIPTIONS ET BeLLES-LetTres (2/9/1768)}

« Il n'y a pas d'idolâtres chez les indigènes, car tous sont Mahométans. Si les Turcs sont Sunnites, les Perses Chiites et les Omanais Bayasites ${ }^{11}$, l'Imam du Yémen, lui, est Zaïdite, tout comme les chefs de tribu de son royaume avec leurs sujets et le plus grand nombre des habitants des montagnes. Les habitants des provinces de Tihama et Taiz sont Sunnites, le plus souvent Chaféites ; en revanche, rares sont dans ces contrées les Hanéfites, les Malékites et les Hanbalites. Deux académies au royaume du Yemen : l'une à Zebid ${ }^{12}$, dont les docteurs sont tous sunnites, l'autre à Dhamar où ils sont zaïdites ${ }^{13}$. Un tribunal suprême a été créé à Sanaa, qui, sous la haute autorité de l'Imam, est compétent pour les causes les plus graves.

Le prince lui-même, l'Imam, est membre de la secte ${ }^{14}$ zaïdite, et le juge suprême de ses sujets pour tout ce qui touche à la religion; il exerce luimême la fonction d'imam dans la mosquée, comme d'autres clercs en son nom. Salué quelquefois du titre de calife, son pouvoir n'est pas moins absolu que celui de l'empereur turc ou de tout autre prince mahométan. Le chérif de La Mecque est un prince séculier, mais ni lui, ni les plus grands pontifes de la Mecque (muftis) pas plus que ceux de Constantinople n' ont quelque autorité dans le royaume du Yémen. Bref, quant à moi, je n'ai trouvé quiconque qui m'aurait rapporté que quelque grand pontife mahométan ait disposé, soit juridiquement, soit hiérarchiquement, de quelque pouvoir que ce soit sur les clercs soumis à d'autres princes. Alors que l'on trouve en Turquie de nombreux monastères de derviches, aucun n'a été porté à ma connaissance ici. On appelle cependant également derviches des mendiants qui feignent la pauvreté, ainsi que d'autres pauvres religieux qui vont lire pour une famille quelques chapitres du Coran sur les tombes. Il n'y a pas

11. Terme synonyme d' "Ibadite », cf. Beschr. Arab., 18.

12. Connue sous le nom de al-madrasa al-Achä̈riya; $\mathrm{CN}$ précise en Beschr. Arab., 225, qu'elle procure à toute la Tihama des clercs et en Reisebeschr. I, 328, qu'on trouve cependant dans la ville un mufti et un cadi chaféites et deux cadis de la secte zaïdite.

13. Connue sous le nom de al-madrasa al-Chamsiya; $\mathrm{CN}$ note en Reisebeschr. I, 407, que 500 jeunes gens y étudieraient, « c'est-à-dire apprennent à lire et comprendre le Coran », et ibid., 235, qu'Abulfeda la mentionne, d'où l'on pourrait supposer qu'elle est déjà assez ancienne.

14. Pour rester au plus près de l'original, nous conservons le mot « secte », bien qu'il ait pris en français moderne un sens péjoratif mal adapté aux « écoles », « branches », « courants », « divisions », « groupes » ou « sous-groupes » des grandes religions, tout particulièrement de la religion musulmane. 
ici de santons ${ }^{15}$ très importuns comme ceux qui passent sur les places publiques du Caire; les Yéménites qui ont bien pris soin de rédiger des règlements assez raisonnables mettent en prison quiconque simulerait la folie après avoir attenté à la vie d'autrui. J'ai moi-même vu quelqu'un dont l'esprit n'était assurément pas perturbé par la boisson - dont les ancêtres étaient des cheikhs chadhilites jadis connus à Mokha pour plusieurs prodiges mineurs -, être l'objet, y compris de la part d'âniers, de la risée des esprits plaisants.

Les Mahométans ne manifestent aucun signe d'aversion envers les adeptes d'autres religions, bien qu'ils les méprisent toutes absolument face à la leur. Et le Chrétien qui oserait frapper un Mahométan ou lui répondrait en le décriant ne courrait pas moins de danger que chez nous les Juifs. Il est permis aux sectateurs de toutes les autres religions d'exercer leur culte, même aux banians ${ }^{16}$, mais pour ces derniers à condition que les portes restent ouvertes ; chacun peut assister au culte des Arabes s'il le souhaite ; les Mahométans trouvant choquante la crémation des défunts, ils (les banians) sont forcés de les ensevelir. Quelques banians sont résidents de la ville de Mokha, mais il n'y en a pas du tout dans les autres villes soumises à l'Imam. Ils n'ont d'ailleurs pas le droit d'amener leurs épouses de l'Inde en raison de quelques grands procès jadis faits par des Arabes à propos de quelque belle baniane. J'ai trouvé peu de Chrétiens parmi les voyageurs, et aucun au royaume du Yémen. On y estime à environ quinze mille le nombre des familles juives, dont la plupart vivent dans un village près de la ville de Sanaa ${ }^{17}$. Des quatorze synagogues qu'ils avaient dans ce lieu, douze ont été détruites il y a sept ans sur l'ordre de l'Imam, dont la cupidité et l'injustice sont haïes de tous ses sujets.

Il est bien connu qu'il n'est permis à personne sauf à un Mahométan de s'approcher des villes saintes plus près que Djedda et Yanbou. Ayant séjourné assez longtemps dans ces deux ports avec mes compagnons, voici ce que j'ai recueilli des indigènes de La Mecque : depuis quelques générations, la souveraineté sur le chérifat ne peut être briguée par un habitant de la Mecque ou de Médine qui ne soit issu du groupe des chérifs du Hedjaz, les Al Bou Numaouis, un groupe constitué de quelques familles plus petites qui se divisent derechef en dhaoui-said, dhaoui al-barakat, etc., et que l'on estime s'élever à au moins trois cents hommes. Le chérif suprême (charif al-achraf) est ordinairement choisi par les chefs de ce groupe, ou, autrement,

15. Santones : ce terme désigne chez César, Pomponius Mela et d'autres auteurs anciens le peuple gaulois qui habitait l'actuelle Saintonge (capitale : Saintes) ; le contexte fait penser à de pauvres diables, mendiants ou un peu fous.

16. Mot du Gujarat, où il signifie « marchand, négociant»; la plupart des banians qui commerçaient au Yémen provenaient de cette province indienne.

17. Le quartier hors les murs de Qa al-Yahud, communément jusqu'à aujourd'hui al-Qa, la plaine en arabe. 
il peut s'emparer du pouvoir : l'un et l'autre doivent être confirmés dans leur souveraineté par l'empereur de Turquie. Pour les grandes colonnes de pèlerins, certaines sont habituellement sous la direction du pacha de Damas, d'autres relèvent de l'émir al-Hadj du Caire, l'autorité suprême étant le sultan. Il y a quelques années, le pacha de Damas avait ôté le pouvoir au Chérif Masaad pour le remettre à Jaafar, frère de ce dernier. Et celui-ci fut contraint aussitôt après le décès du pacha de le rendre à son frère, que le sultan confirma dans sa souveraineté pour la seconde fois. En tout cas, quel qu'il soit, celui qui détient le pouvoir à La Mecque importe peu au sultan. Le sultan reçoit l'argent qui lui est légué par les testaments dans toutes les provinces où règne la secte des Sunnites, plutôt que les revenus provenant de l'Arabie, dont la plus grande part revient au chérif et aux grands de La Mecque ; on dit que quelques citoyens particuliers de cette ville auraient également une part en qualité de * prêtres de la Kaaba. Envoyé par le sultan, c'est ainsi qu'un autre pacha arrive chaque année dans la ville de Djedda ; or il est obligé de partager à égalité avec le chérif de La Mecque les revenus provenant des redevances, alors que sa quote-part suffit à peine pour assumer les dépenses indispensables. Sont également soumis pour moitié aux prélèvements du sultan les gouvernements des villes de Djedda, La Mecque et Médine, et, si je ne me trompe, celui de la ville de Yanbou également ; l'autre moitié revient au chérif, qui assure encore seul la protection de XVI autres villes plus petites, telles que al-Taif, al-Qunfuda, Haïl, etc. Au-delà de la place forte de Haïl cesse la domination du chérif. Entre cette dernière et celle du chérif d'Abou Arich sont les territoires occupés par les Arabes Scènites ${ }^{18}$, alors que tout le reste de l'Arabie relève de la Syrie. Tous s'occupent si peu du pouvoir du sultan que les grandes colonnes de pèlerins, pour se concilier leurs bonnes grâces, se sentent tenues à quelque présent ; le pacha de Damas ayant refusé de payer ce quasi-impôt et ayant osé punir ceux qui en étaient arrivés à accepter ce présent, les Arabes en colère s'armèrent tous ensemble pour, à la première occasion, piller la colonne tout entière.

Exceptés les chérifs descendants de Mahomet, il en subsiste quelques autres de la tribu des Qoraiches ${ }^{19}$, auxquels il importe de sauver la mémoire de leur famille issue de cette tribu. Car dans leur famille est héréditaire la charge de *mufti de la secte chaféite, que remplit aujourd'hui l'Imam Abd al-Wahab Tabari, auquel incombe d'ordinaire (2) ${ }^{20}$ la garde de la clé de la

18. Pline, HN., 5,65 et 6,145 et Strabon, Geog. XVI,1,27, évoquent ce peuple qui nomadise « sous tente »; Strabon le localise dans le désert sur la rive gauche de l'Euphrate en face de Zeugma ; F. Millar, The Roman Near-East, Cambridge (Ma)/London 1996, 439, considère Scènites, Arabes et Sarrasins comme des brigands du désert.

19. On écrit aussi Koreiche.

20. L'énumération, légèrement différente, est plus claire dans Besch. Arab., 17 , voir ci-dessous. 
Kaaba ; Mahomet a déclaré dans un édit que cette charge particulière avait été accordée par Dieu lui-même à Othman ibn Talha et à ses descendants, (3) la charge de *mufti de la secte hanbalite, (4) la charge de Cheikh Mohammad Al-Janajani. »

\section{BESCHREIBUNG ARABIENS (1772)}

\section{a) XI-XII (extrait de la préface)}

«Sur la religion mahométane, on peut interroger sans crainte les négociants, habitués à fréquenter toutes les nations, et les savants pauvres, auxquels on peut faire de petits présents, on peut même leur en parler librement. Tout en notant que, naturellement, les Arabes ne laisseront pas non plus quiconque, et encore moins un étranger, mépriser leur religion. Si l'on veut parler de religion avec le peuple arabe, on peut toujours craindre des réponses désagréables. En revanche, si l'on se comporte avec calme envers les Arabes, on peut en retour s'attendre à autant de courtoisie de ces Mahométans qu'en montrent aux Juifs en Europe les Chrétiens raisonnables. On peut d'ailleurs déduire des remarques de certains Européens, qui ne sont pas contents en général des Mahométans, que les Arabes ne sont pas que grossiers et cupides. M. de Breidenbach ${ }^{21}$ parle toujours avec irritation des Arabes lorsqu'il doit s'acquitter d'un péage, d'un pourboire, etc., et plus loin dit pourtant qu'il a trouvé les bateliers vénitiens plus cupides que les Sarrasins. Otter ${ }^{22}$ assure qu'en Perse, Arabie et Turquie aucun rahdar $^{23}$ ne l'a autant contrarié que les douaniers français à son retour à Marseille. »

\section{b) 17-18 (registres généalogiques et charges religieuses)}

«Ceux qui règnent dans les pays arabes ne sont pas seuls à tenir avec ferveur des registres généalogiques, car on trouve aussi à La Mecque, outre les chérifs, encore des familles qui descendent réellement des Qoraiches et tiennent à pouvoir le prouver, car certaines charges dans cette cité sont devenues héréditaires dans leurs familles. Notamment :

1) la charge de celui qui garde la clé de la Kaaba, car sur ordre de Mahomet cela doit rester à perpétuité dans la famille d'Othman ibn Talha

21. Bernhard von Breydenbach est allé à Jérusalem en 1483, son récit en allemand a été publié vers 1505, et des versions latines en 1490 et 1502 .

22. Jean Otter, Voyage en Turquie et en Perse, Paris 1748.

23. Mot persan ancien (prononcer rordor): agent chargé du contrôle des voyageurs. 
[Sale ${ }^{24}$, Coran chap. 4, p. 68 ; Herbelot ${ }^{25}$, Bibl. orient. p. 221]. Celui qui assume actuellement cette charge a pour nom Cheikh Mohammad Chaibi de la tribu des Bani Chaiba qui descend des Bani Abd al-Dar, et on le tient véritablement pour un descendant d'Othman ibn Talha précédemment évoqué. 2) la charge de mufti de la secte chaféite. Le titulaire actuel s'appelle Imam Abd al Wahab Tabari. 3) la charge de mufti de la secte hanbalite. 4) la charge d'un cheikh savant, qui se nomme Mohammad al-Janajani. »

\section{c) 18-27 «Religion des Arabes »}

«Il est connu que, dans la religion mahométane comme dans les autres, on rencontre diverses sectes, les Turcs se rattachant à la secte sunnite et les Perses à la secte chiite. Même en Arabie où la religion mahométane a son origine et règne encore, on trouve cette différence, que l'on peut présenter ainsi :

1) La secte sunnite. Elle est la plus nombreuse dans la péninsule. Elle est aussi la plus remarquable pour cette raison que les habitants des villes de La Mecque et Médine y adhèrent.

2) La secte chiite a ses adeptes dans quelques régions orientales de l'Arabie, mais son siège principal sur le golfe Persique, principalement dans l'île de Bahrein. Les Metoualis ou Mutalis de Syrie sont également chiites, du moins leurs sectes se ressemblent-elles beaucoup.

3) La secte zaïdite* domine au Yémen, elle trouve son origine en Zaïd ibn Ali ibn Hussein ibn Ali. Relèvent sans doute de cette tendance les Zaïdianiens que mentionne Sale en p. 175 de son avant-propos à la traduction du Coran.

4) La secte bayasite ou bayadite ou *ibadite règne en Oman et ses adeptes sont nommés Ibadites en p. 49 et 56 dans la traduction de la description de la terre du Chérif Idrissi ${ }^{26}$. Elle a probablement son origine dans les ennemis du calife Ali, si fortement battus qu'il n'en restait que neuf, dont deux, selon une observation de l'auteur de l'histoire générale du monde, allèrent en Oman. Ces quatre sectes sont les plus distinguées des sectes mahométanes parce qu'elles ont des princes puissants comme adeptes. Mais on en trouve d'autres en Arabie.

5) Les Bédouins de la frontière entre Hedjaz et Yémen appelleraient leur secte messalite* et auraient des conceptions particulières en matière de religion. Ils pratiquent la circoncision d'une manière qui diffère de celle des autres Mahométans, comme nous le verrons plus loin²7.

24. George Sale, The Koran, commonly called the Alcoran of Mohammed, Londres 1734

25. Bartholomé d'Herbelot, Bibliothèque orientale, Paris 1697.

26. Idrissi, Geographia Nubiensis (original arabe), version latine Paris 1619.

27. Cette méthode particulière est exposée dans Beschr. Arab., 269. 
6) Un Cheikh Makrami ${ }^{28}$ de Najran et un autre Cheikh Abd al-Wahab ${ }^{29}$ dans le Nejd ont fondé il y a quelques années des sectes particulières, j'ignore encore leurs noms. Mahomet aurait dit que plus de 70 sectes différentes étaient apparues dans les religions des Juifs et des Chrétiens, et que sa nouvelle religion se diviserait en autant de sectes à cause du manque d'unité de ses adeptes. Je n'ai rencontré personne qui aurait pu me donner sur toutes une information détaillée. La secte djedjal ${ }^{* 30}$, à laquelle se rattachent les habitants de Mekran ${ }^{31}$, et les sectes khaehreari* et merdinar ${ }^{*}$, à laquelle se rattachent les Balouches, également une nation du sud-ouest de la Perse ${ }^{32}$, peuvent cependant être classées parmi les sectes mahométanes; car les adeptes de toutes ces sectes placent Mahomet parmi les prophètes ; et ils ne font pas que se nommer Mahométans, le Coran est bien aussi chez eux le code le plus élevé devant leurs tribunaux religieux et civils. Toutefois, entre eux, ils se tiennent pour Kharijites* ou Rafidites*, c'est-à-dire hérétiques. À Bassora, le mot rafidi signifie toujours chiite, et un Kharijite est un Bayasite. Pocock appelle ces derniers Khaouarijites, Specimen histor. Arabum $^{33}$, p. 26.

Les dogmes des Sunnites et Chiites sont connus, je noterai néanmoins dans ma description du voyage divers points que j'ai pu recueillir de la bouche de leurs adeptes. Je n'ai pas eu avec les croyants des autres sectes mahométanes mentionnées des rapports si proches qu'ils m'auraient permis d'apprendre d'eux directement les principes de leur religion. Je dois donc me satisfaire de n'exposer que le peu que j'ai appris sur les Sunnites.

Les Zaïdites croient, comme d'ailleurs les adeptes de chacune des autres sectes, qu'ils sont les seuls à enseigner la vraie religion sans l'altérer, et se considèrent comme les plus nobles des Mahométans. Comme les Sunnites de La Mecque n'admettent que les mosquées des quatre sectes (chaféite,

28. Détails sur ce cheikh dans Beschr Arab., 272-274 ; ce nom reste celui du chef de la communauté des Ismaélites Daoudis Sulaymanis de Najran et du Yémen. La majorité de la communauté est désormais en Inde.

29. S'il s'agit bien de Mohammad ibn Abd al-Wahab, ce serait vraisemblablement dans les sources occidentales la première référence au réformateur dans le Nejd, fondateur de la tendance wahabite avec ses alliés Al-Saoud.

30. Il ne semble pas que ce mot apparaisse dans Les schismes dans l'Islam, Henri Laoust, Paris ${ }^{2}$ 1983; le Professeur Haykel se demande toutefois si, s'agissant d'habitants du Mekran, que l'on appelle zikri ou dhikri (de dhikr, le cercle), il ne faudrait pas lire dajjal = faux prophète, car ils reconnaissent Sayyid Mohammad Jaunpuri (1443-1505) qui s'est proclamé « Mahdi » mais a été violemment combattu.

31. Région côtière de la Perse à l'ouest du détroit d'Ormuz.

32. Il serait plus exact de dire «du sud-est de la Perse » s'il s'agit des habitants du Balouchistan actuel, divisé entre Iran et Pakistan.

33. Edward Pocock, Specimen historiae Arabum sive Gregorii Abu'l Faragii..., Oxford 1663. 
hanéfite, malékite et hanbalite) qu'ils tiennent pour orthodoxes à côté de la Kaaba, les Zaïdites se construisent en plus dans l'air, juste au-dessus de cette dernière, une cinquième mosquée invisible, et prétendent par là avoir un droit sur la Kaaba plus proche que les Sunnites. Ces derniers, qui ne peuvent les empêcher de construire des mosquées aériennes, frappent d'une capitation élevée leurs pèlerins, ainsi que les Persans depuis quelques années, lorsqu'ils vont à La Mecque et ne peuvent ou ne veulent se montrer comme de parfaits Sunnites dans toutes les cérémonies. Les Zaïdites tiennent Mahomet pour le plus grand prophète, comme les Sunnites et Chiites, et affirment avec ces derniers qu'une injustice a été commise envers Ali lorsque Abou Bakr, Omar et Othman lui ont arraché le califat des mains. Ils ne grondent cependant pas contre ces trois califes comme le font les Chiites. Bien plus, il semble qu'il leur soit aussi indifférent qu'aux Sunnites de savoir qui aurait le premier après Mahomet dirigé ceux que l'on appelle Musulmans (croyants orthodoxes). Les Zaïdites ne croient pas non plus à la lignée des douze imams des Chiites. Mais je présume qu'ils ont un respect particulier pour les quatre premiers, soit jusqu' au fondateur de leur secte. Les Sunnites de la Tihama ${ }^{34}$ prétendent que les Zaïdites ne manifestent aucune vénération pour les saints dans leurs prières, et que l'Imam du Yémen, qui se rattache à cette secte, ne se fait aucun scrupule de détruire les mosquées édifiées en l'honneur de saints sunnites célèbres, et de s'emparer des revenus. Bien que n'ayant pas personnellement prêté une grande attention aux prières lors des cérémonies des Zaïdites, il m'a cependant semblé qu'ils ne sont pas aussi consciencieux dans leur pratique de la prière que les Mahométans du Nord. On m'a toutefois raconté qu'ils ne se contentent pas, comme les Sunnites, de se laver avant la prière, mais qu'ils enlèvent leurs braies pour être absolument certains qu'ils n'ont rien d'impur sur le corps lorsqu'ils paraissent devant Dieu pour se recueillir. Ce dernier renseignement n'est guère fiable. Car l'homme de la rue au Yémen ne porte ni braies ni chemise, seulement un linge autour des hanches, et il ne le retirera évidemment pas pour la prière, car alors il apparaîtrait complètement nu ${ }^{35}$.

Les Sunnites, Chiites et Zaïdites manifestent tous une certaine vénération pour les descendants de Mahomet. Les Bayasites, qui ne veulent en aucun cas leur accorder de préférence devant les autres Arabes, affirment au contraire que tous les Mahométans ont dès leur naissance un même droit à tous les titres honorifiques et à toutes les plus grandes charges tant spirituelles que profanes. C'est pourquoi le régent du territoire auquel appartient le port connu de Mascate se nomme imam, et probablement pour la même raison le régent à Sanaa se nomme-t-il calife, sans faire dériver son origine

34. Plaine côtière du Yémen (rive orientale de la Mer Rouge).

35. Malgré ses doutes, $\mathrm{CN}$ semble avoir été bien informé : jusqu'à nos jours, certains Zaïdites enlèvent leurs sous-vêtements avant la prière, dans la conviction que cela les rend plus purs au regard du rite. 
de Mahomet. Les boissons fortes sont interdites aux adeptes de cette secte tout autant qu'à tous les autres Mahométans. Les Bayasites ne fument pas de tabac et ne boivent pas de café. Mais ils sont si courtois envers les étrangers qu'ils leur en offrent. L'actuel Imam lui-même avait lors d'une visite fait offrir les deux à un voyageur sunnite venu à Rostaq ${ }^{36}$, car il est fort impoli chez les autres Mahométans de ne pas régaler les étrangers. Ce régent permet non seulement aux étrangers mais aussi aux plus petits de ses sujets de s'asseoir en sa présence, et même tout près de lui. Tous, tant lui que ses coreligionnaires, évitent tout luxe dans leurs vêtements, dans leurs habitations et leurs mosquées, et la justice, aussi bien envers eux qu'envers les indigènes, est très strictement observée. Il est vrai que tous les régents de cette secte n'ont pas gouverné avec tant de justice et de complaisance. L'imam dont il vient d'être question s'adonnait à la boisson et à d'autres vices. Il fut donc déposé et sa famille exclue du gouvernement comme cela sera observé ci-dessous.

On m'a raconté à Mascate à propos de l'origine de la secte djedjal ${ }^{37}$ qu'un célèbre clerc aurait dit au Mekran que Dieu leur procurerait un grand miracle lorsqu'ils abattraient les arbres dans une certaine région. On aurait à cet effet établi un jour de prière générale, abattu les arbres, et trouvé dans l'un de ces derniers, un livre à la main, un vieil homme respectable, qui serait devenu le fondateur de la secte. Voilà les contes que l'on obtient des adeptes d'une secte mahométane lorsqu' on s'informe auprès d'eux des principes des autres. Selon le récit du prince Kantemir, la secte des Chiites devrait sa fondation à un miracle du même genre, Histoire de l'Empire ottoman par Schulz, p. $276^{38}$.

Je n'ai pas entendu parler, ni chez les Zaïdites au Yémen ni chez les Bayasites en Oman, de derviches (moines), ni qu'ils aient des monastères dans ces pays, il est vrai que je ne me suis pas renseigné sur ce point. Je présume cependant que Ahmad ibn Alwan ${ }^{39}$, bien connu dans la partie méridionale du Yémen, qui était sunnite, a fondé un ordre et que ses disciples disposent d'une sorte de monastère (tekye) dans les villes du Yémen où n'habitent que des Sunnites. On trouve dans les grandes villes turques, probablement aussi à La Mecque, Médine, Djedda et Yanbou, beaucoup d'ordres monastiques divers tels que: nakchbandi, khalouati, kadiri, adhami, ichaqi, badaoui, bektachi, rifai, maoulaoui, kalandari ou

36. Bourgade en Oman.

37. Cf. note 30 ci-dessus

38. En réalité État général de l'Empire ottoman depuis sa fondation jusqu'à présent. Geschichte des osmanischen Reichs von seiner Stiftung an bis auf gegenwärtige Zeiten. Nach dem französischen des Hrn de la Croix, mit Verbesserungen von Johann Christoff Fridrich Schulz, 3 vol., Frankfurt und Leipzig, 1769-1772.

39. Son mausolée à Yafrous au sud de Taiz est un centre de pèlerinage. 
karendali $^{40}$, etc. À Mokha on appelait également derviches les quelques mendiants qui parcouraient isolément les rues en chantant, ainsi que de pauvres religieux qui pour une petite obole lisent un chapitre du Coran sur les tombes.

Au cours de notre voyage de Mokha à Taiz j' ai vu un Sunnite, descendant du célèbre Cheikh Chadhili de Mokha, qui était vraiment puéril. Nos âniers et chameliers, également des Sunnites, ne lui manifestaient aucun respect, mais plutôt riaient, couraient et sautaient avec lui, parce qu'ils l'y trouvaient disposé, et ne l'appelaient cheikh qu'en raison du père de sa tribu, car, comme ils le disaient eux-mêmes, ils l'auraient sans cela tenu pour un simple d'esprit. Ceux que l'on appelle santons, qui parcourent en si grand nombre les rues du Caire, ne trouveraient peut-être pas leur bonheur chez les Sunnites du Yémen. Comme les Zaïdites et les Bayasites n'ont aucun saint, ils n'ont sans doute ni derviches ni santons.

Comme les Turcs et les Persans se sont livrés de nombreuses guerres sanglantes, qui ont toujours été considérées comme des guerres de religion, de même les Sunnites et les Chiites sont si montés les uns contre les autres qu'ils se haïssent plus entre eux que les adeptes de religions toutes différentes, ou que ceux qu'ils appellent incroyants. C'est ainsi que les deux permettent aux Chrétiens et aux Juifs de bâtir des églises et des synagogues dans leurs pays. Les Chiites ne souffrent néanmoins en Perse aucune mosquée des Sunnites, qui de leur côté ne permettent pas aux Chiites en Turquie de célébrer leur culte en public, sauf près des tombes de leurs soidisant messagers ${ }^{41}$ que l'on trouve dans la région de Bagdad : cette liberté, ils la paient cher. Dans le petit royaume du Yémen, où les Sunnites sont pourtant presque aussi nombreux que ceux qui les dominent, les Zaïdites, les adeptes de ces deux sectes s'entendent relativement bien. Je n'ai pas remarqué qu'ils haïssent leurs coreligionnaires d'autres sectes, mais plutôt, comme les Européens vis-à-vis des Juifs, qu'ils les considèrent avec dédain et mépris.

Si les Mahométans n'apprécient pas les soi-disant hérétiques et incroyants autant qu'eux-mêmes, je n'ai quand même jamais entendu dire qu'ils les brûlent à cause de la religion, à moins qu'ils n'aient commis un forfait, par exemple s'ils ont eu des relations avec une femme mahométane. La punition peut même alors leur être ordinairement épargnée s’ils deviennent mahométans. Mais ceux qui ont prononcé des blasphèmes sont irrémédiablement punis de mort, même si le criminel est un Mahométan. Les exemples de

40. Noms de confréries soufies.

41. CN utilise le mot allemand «Apostel», apôtre, alors que les disciples du Christ sont normalement appelés «Jünger»; comme ce dernier terme se trouve également dans le texte de $\mathrm{CN}$ et ne peut être traduit autrement que par « apôtre », nous avons choisi de traduire ici «Apostel» par «messager », de l'étymologie grecque. 
tels cas ne sont pas rares. Pendant mon séjour à Bagdad un janissaire réclamait le paiement d'une créance à un habitant qui l'exhortait, avec une mine pensive, à se rappeler Dieu et le Prophète, à ne pas se mettre en colère, et à attendre avec patience qu'il soit en état de payer. Le janissaire finit par se fâcher. Et le débiteur lui ayant à nouveau rappelé Dieu et le Prophète, il répondit, dans sa colère et sa hâte, par un blasphème. L'hypocrite débiteur rameuta des témoins, le janissaire fut chassé du corps des janissaires le jour même, et pendu le jour suivant.

On ne trouve pas seulement quelques Juifs dans la plupart des provinces d'Arabie, qui vivent disséminés sous la domination des Mahométans, mais aussi presque des tribus entières qui ont leurs cheikhs indépendants dans la région montagneuse du Hedjaz autour de Khaybar. Lorsqu'un nombre suffisant d'entre eux se trouve dans une ville, ils habitent alors volontiers les uns près des autres, et séparément des Mahométans. Ce qui explique qu'au Yémen ils aient leurs familles et synagogues dans de multiples villages près des grandes villes. Je n'ai pas entendu dire que les Chrétiens aient une seule église en Arabie, Bassora exclue, bien que leur nombre ait été notable dans le passé (Sales preliminary discourse, p. 22. Pocock Spec. Hist. Arab.). On rencontre pourtant encore dans la province de al-Hassa ${ }^{42}$ de nombreux Sabéens ${ }^{43}$, que l'on appelle aussi Chrétiens johannites ${ }^{44}$.

Au Yémen, en Oman et à Bassora se trouvent également de nombreux banians, les soi-disant païens originaires de l'Inde. Les Mahométans les méprisent beaucoup plus que les Chrétiens et les Juifs, d'abord et surtout parce qu'ils n'ont pas de livres sacrés, c'est-à-dire ni les livres de Moïse, ni l'Évangile ou le Coran, et aussi, selon eux, parce qu'ils ne savent rien de Dieu. Un Mahométan qui épouse une Chrétienne ou une Juive souvent ne tente pas de lui faire renier sa foi. Mais les Sunnites disent qu'ils n'épouseront en aucun cas une baniane, ou une parsi (ceux que l'on appelle les adorateurs du feu $)^{45}$ et je ne crois même pas qu'il leur soit permis de manger

42. Au nord-est de l'Arabie Saoudite, le long du Golfe Arabo-Persique. Noter qu'en p. 94 de Beschr. Arab. CN indique que les Sabéens/Johannites, peu nombreux cependant autour de Bagdad, parleraient et écriraient encore leur ancienne langue, le plus savant étant un forgeron.

43. La sourate II, 59 pose le principe de l'égalité des quatre religions islamique, juive, chrétienne et sabéenne [Régis Blachère (Coran, Paris 2005) se demande à propos des Sabéens (localisés dans le Harran, nord de la Mésopotamie) s'il ne s'agirait pas d'une interpolation postérieure à Mahomet]. Ces Sabéens pourraient être des Mandéens, que l'on trouve dans le sud de l'Iraq et la province iranienne du Khouzistan (autour d'Abadan).

44. Doctrine ésotérique (en principe réservée aux initiés) fondée sur l'Évangile de St-Jean.

45. Le mot «parsi » désigne un adepte de la religion mazdéenne (du nom du dieu, Mazda) ou zoroastrisme, le feu, par analogie avec le soleil, symbolisant le dieu ; son centre principal se trouve aujourd'hui autour de Bombay. 
avec eux [n : guri, c'est ainsi que les Arabes appellent aussi bien les banians que les parsis probablement du mot geber, ce qui semble-t-il a conduit les Turcs, venus les premiers en Perse, à appeler giaour les soi-disant adorateurs du feu, et ensuite les Chrétiens. On appelle cafres les païens originaires d'Afrique ${ }^{46}$. Au Yémen on ne permet pas aux banians d'incinérer leurs morts ni d'amener leurs femmes, parce que, un jour, une dispute s'était élevée entre les Mahométans de Mokha à cause d'une belle Indienne. Mais à Mascate les adeptes de toutes les religions peuvent vivre selon leurs propres lois. Les banians ont là non seulement un endroit qui leur est réservé, en dehors de la ville en bord de mer, où ils peuvent incinérer leurs morts, mais en outre ils ont leurs épouses indiennes avec eux. L'un des banians de là-bas auquel je rendais visite assidûment avait dans son habitation, à la vue de tous, beaucoup de statuettes en porcelaine, sans crainte que les Mahométans lui en fassent reproche. [n: Je ne sais pourtant pas si les Mahométans de la secte bayasite sont ennemis des figurations ${ }^{47}$. Leurs voisins les Chiites de Perse et les Sunnites d'Inde ont eux-mêmes des peintures, et tous les Sunnites de Turquie ne sont pas vraiment de si grands ennemis des figurations qu'on le croit peut-être. J'ai vu chez un savant au Caire non seulement des gravures, mais aussi un buste en plâtre. Il ne montrait ce dernier qu'à ses plus proches amis, et jamais au peuple ignorant, afin qu'on ne l'accuse pas d'idolâtrie. J'ai également vu deux peintures dans une maison de campagne du sultan à Constantinople]. J'ai vu beaucoup de banians en Perse également, mais je n'ai pas découvert quelle liberté on leur laissait. Ceux de Bassora peuvent incinérer leurs morts en dehors de la ville. Dans les autres villes soumises aux Turcs autres que Bagdad, Djedda et Suez, je n'ai pas vu de banians. Il paraît qu'il y en a encore quelques-uns à Souakin et Massaoua ${ }^{48}$ qui subissent les mêmes restrictions qu'au Yémen. Je me souviens p. e. avoir entendu dire que, à Massaoua il y a quelques années, on avait fini par contraindre à devenir lui-même mahométan un banian ayant vécu plusieurs années avec une Mahométane avec laquelle il avait eu des enfants.

Il semble que les Mahométans d'Inde haïssent les adeptes d'autres religions encore moins que les Arabes. En tout cas, on racontait qu'à Sourat ${ }^{49}$, où le gouvernement est mahométan et une grande partie des sujets sont de

46. Le mot «cafre» visait les non-musulmans des pays au sud des régions africaines converties à l'Islam.

47. Dans Reisebeschr., t. I, 247, Niebuhr raconte qu'ils se trouvent devant une petite chapelle dans l'escalier entre le cloître de $S^{\text {te }}$ Catherine et le mont Sinaï : "Mes deux cheikhs arabes firent devant elle une prière recueillie et lorsque nous fûmes entrés, ils embrassèrent les images du Christ et de la Vierge Marie, car ils étaient mahométans, et firent encore une longue prière... ».

48. Ports de la Mer Rouge, au Soudan et en Érythrée respectivement.

49. Ville d'Inde, au nord de Bombay. 
prétendus païens de diverses religions et sectes, tous ces gens vivaient en bonne concorde. Les banians sont en effet des sujets très paisibles. Au lieu de faire comme les prêtres des nombreuses sectes chrétiennes qui se donnent beaucoup de peine pour baptiser les incroyants, et comme les Mahométans qui circoncisent et protègent ceux qui veulent adopter leur foi, les brahmanes ${ }^{50}$, banians, rajputs ${ }^{51}$, etc. n' acceptent aucun étranger dans leurs communautés. Tout au contraire chassent-ils de leurs assemblées la racaille débraillée, et ainsi procurent parfois de nouveaux prosélytes aux Chrétiens et Mahométans. »

\section{d) 40-46 « Comportement des Mahométans}

envers les adeptes d'autres religions »

«Les Arabes se montrent beaucoup plus courtois envers les étrangers que les Turcs. Les Européens peuvent s'attendre au Yémen et en Oman ainsi qu'en Perse à autant de courtoisie des indigènes que nous pourrions en montrer à ces Mahométans s'ils venaient en Europe. Et si l'on rencontre là des gens qui se montrent discourtois envers les étrangers, peut-être trouve-t-on aussi des voyageurs européens qui y ont donné motif en se considérant comme importants mais en regardant dédaigneusement tous les Mahométans, et en ne connaissant pas les mœurs du pays et en ne voulant les respecter ${ }^{52}$. Comme les Mahométans, dans toutes les villes où j'ai rencontré des commerçants européens, exigent d'eux moins de droits de douane que de leurs propres sujets, on devrait croire que ceux-là au moins qui ont part au gouvernement s'efforceront également dans d'autres occasions de gagner l'amitié des Européens.

En revanche, je crois avoir remarqué que la plupart des Turcs que j'ai connus nourrissent vraiment de la haine pour les Européens. Peut-être parce qu'ils se rappellent les nombreuses guerres sanglantes qu'ils se sont livrés. Le nom des Turcs ne peut être aussi redoutable à nos enfants que le nom des Européens ne l'est aux jeunes Turcs. Il semble même que ceux qui sont au service des Européens ne paraissent pas considérer leurs maîtres comme leurs bienfaiteurs mais comme des gens sous leur protection. Par contre ils sont méprisés par leurs compatriotes parce qu'ils s'abaissent à manger le pain des Européens. À Constantinople, on a coutume de les appeler gardiens de cochons. Les Européens sont très haïs à Damiette et

50. Membres de la caste sacerdotale, la première en Inde (du sanskrit « détenteur d'une formule au pouvoir religieux et au caractère magique »).

51. Membres de la caste militaire (du sanskrit «fils de roi »); ils sont actuellement Hindouistes au Rajastan et Musulmans au Pakistan.

52. CN condamne avec force, Reisebeschr. II, 42, n. 1, un acte dont AnquetilDuperron semble malheureusement être fier, voir son Zend-Avesta, Paris 1771, I, 390. 
Damas en particulier, et sont également considérés avec beaucoup de mépris par la populace du Caire. Au contraire, en Arabie et en Perse où les habitants n'ont jamais eu de guerre avec les Européens, ces derniers peuvent s'attendre à plus de politesse également de la part de la populace.

C'est de la même façon que les Chrétiens orientaux ne peuvent attendre le même accueil de tous les Mahométans. Les Arméniens et Géorgiens semblent se trouver très bien en Perse. Ils seront parfois maltraités par la populace, et les Mahométans ne rechercheront pas leur compagnie s'ils ne cherchent pas à s'en faire aimer. Ils peuvent cependant parvenir à de hautes charges militaires sans être contraints de changer de religion. J'ai moi-même connu à Chiraz un khan, qui était un Chrétien géorgien, et un capitaine d'artillerie, qui était arménien. J'ai rencontré dans une petite armée du Wekil Karim Khan divers sous-officiers géorgiens qui étaient chrétiens. Alors que les Turcs ont si peu confiance dans les Chrétiens, ou les estiment si peu qu'ils ne veulent même pas en accepter un comme simple soldat dans l'armée du sultan. En définitive, ils se comportent honteusement envers leurs concitoyens chrétiens en comparaison avec les autres Mahométans. Les Arabes appellent les Chrétiens nasara ou nasrani. ${ }^{53}$ Comme ils ne peuvent parvenir chez eux à des postes honorables et que les Chrétiens les plus en vue qui habitent parmi eux sont des commerçants, ainsi nommet-on en Égypte celui qui est vêtu convenablement khaouaja ou basarga, les deux mots signifiant commerçant. Et ceux qu'ils ne tiennent pas pour commerçants mais pour artisans, ils les appellent maallim ou muallim, c'est-à-dire maître ${ }^{54}$. Voyageant comme Chrétien oriental, et ayant souvent adopté par commodité un nom oriental, sans nier que j'étais un Européen, je m'appelais en Égypte et du côté occidental de l'Arabie Khaouaja Abdallah. On nomme agha en Perse aussi bien les Mahométans que les Chrétiens, et je m'appelais donc là-bas Abdallah Agha, c'est-à-dire monsieur Abdallah. Je bénéficiais du même honneur à Mascate, Bassora et Bagdad. En Syrie, c'est maallim que l'on nomme les commerçants chrétiens, c'est donc maître que l'on me nommait dans ces régions. En Anatolie, où le turc est la langue principale, la courtoisie des Mahométans envers les Chrétiens semble avoir pris fin. Car là-bas les Turcs nommaient les Chrétiens orientaux presque toujours giaourler (incroyants), un nom si méprisant que dans leur colère ils en honorent leurs chevaux ou autres animaux. De sorte que même l'homme qui m'avait loué des chevaux entre Alep et Konie, que je pouvais donc considérer comme mon conducteur, m'appelait aussi giaour. Dès le début je lui dis que je n'étais pas un giaour, mais un Européen, de ceux qu'on appelle Francs dans toute la Turquie, l'Arabie et la Perse : j'obtins ainsi que par la suite il m'appelle toujours par ce nom, ou Abdallah.

53. Ce sont les Nazaréens, de Nazareth, lieu où vécut Jésus.

54. Non pas au sens de «patron », mais de «maître artisan », expert dans une technique manuelle. 
Comme les Turcs donnent à leurs concitoyens chrétiens un nom si méprisant, on peut imaginer qu'ils ne sont pas plus courtois dans le reste de leur comportement à leur égard. Ils n'obligent pas seulement les Chrétiens à porter un certain signe qui permette de les distinguer, ils peuvent aussi leur faire payer la capitation (kharaf) ${ }^{55}$ (en effet, les Orientaux ne tiennent pas de listes régulières sur ce point) ; et les Turcs à Constantinople vont même parfois jusqu'à demander aux Chrétiens qui passent de leur balayer la rue, et d'enlever les ordures, ou de leur payer quelque chose pour être dispensés de ce travail [ $\mathrm{n}$ : Il semble également qu'il y a quelques centaines d'années les Chrétiens orientaux n'ont guère montré de courtoisie envers les Juifs qui vivaient sous leur domination à Constantinople. Itinerarium Benjamini Tudelensis ${ }^{56}$, p. 31]. Cela n'est probablement pas approuvé par les autorités. Un sujet chrétien du sultan n'oserait pas attaquer un Mahométan en justice pour une bagatelle, et c'est pourquoi on trouve encore chez les janissaires et autres Turcs mal pensants quelques individus suffisamment insolents pour avoir de telles exigences. En cas de liesse publique, p. e. à l'occasion de la naissance d'un prince ou d'une princesse, c'est là qu'ils sont les plus désagréables, il est en conséquence indiqué pour les Juifs et les Chrétiens de ne pas paraître dans la rue ces jours-là. Parmi les nombreux exemples de comportement arrogant de Turcs à l'égard de Chrétiens orientaux auxquels j'ai moi-même assisté, je veux raconter seulement le suivant. Un Turc, rencontré sur une route de campagne d'Asie Mineure au moment où il voulait monter à cheval, a obligé un marchand grec de notre caravane, qui ne le connaissait même pas, à descendre de cheval et à lui tenir son étrier. Une attitude dont pour sûr un Arabe aurait honte. C'est ainsi qu'un cheikh, qui nous avait loué 17 chameaux, m'a plus d'une fois laissé monter sur son dos et de là sur mon chameau.

Les Mahométans en Égypte, en particulier ceux d'origine turque ou qui ont été élevés à la turque, manifestent un orgueil immodéré vis-à-vis des Chrétiens. Ceux-ci ne peuvent guère en vérité se plaindre de ne pouvoir monter à cheval dans les rues du Caire, car les ânes y sont très beaux, et non seulement la plupart des Mahométans mais également les Mahométanes les plus distinguées montent des ânes. Seuls les Juifs et les Chrétiens qui au début, par respect ou crainte peut-être, descendaient de leur monture lorsqu'ils rencontraient un Mahométan distingué à cheval avec une suite importante, sont de nos jours tenus de faire cet honneur à plus de trente

55. CN semble avoir confondu la kharaf, taxe foncière payable par tous les sujets, quelle que soit leur religion, et la capitation (jizya) imposée aux seuls non-Musulmans.

56. Il s'agit du récit du voyage au Proche-Orient du rabbin Benjamin de Tudèle (localité de Navarre) au XII ${ }^{\text {e }}$ siècle ; CN le cite longuement, en français, dans Beschr. Arab., 195. 
des plus distingués de la ville. Quand de telles personnalités paraissent dans la rue, elles envoient chaque fois en avant un serviteur qui doit rappeler aux Juifs et aux Chrétiens et même aux Européens qu'il rencontre à âne qu'ils doivent descendre immédiatement, et il peut au besoin les y obliger avec un grand bâton qu'il tient toujours à la main.

J'ai rencontré trop peu de Chrétiens orientaux pour me permettre d'oser porter un jugement sur le caractère de ces nations. Je crois cependant qu'ils sont souvent eux-mêmes responsables du mauvais accueil qu'ils reçoivent des Turcs. C'est ainsi que la majorité des petits marchands grecs que j'ai connus en Asie Mineure m'a semblé constituée de bas flatteurs et bavards, et de telles gens ne peuvent attendre beaucoup de courtoisie des Turcs sérieux et fiers. J'ai souvent vu dans cette région des marchands grecs s'affairer à tenir l'étrier, lorsqu'ils voulaient monter ou descendre, non seulement à des Turcs distingués mais même à leurs katerdjis, c'est-à-dire à ceux qui leur avaient loué des chevaux et des animaux de bât. Ils se comportaient avec ces katerdjis de façon si commune que l'un de ces derniers s'est permis plusieurs fois de demander à son marchand de lui gratter le dos. Un serviteur turc de deux Grecs nommait ses maîtres giaourler, ou l'un christophelo et l'autre papas ugli, et ils l'appelaient Bekir Agha. Les Grecs allaient jusqu'à se nommer eux-mêmes giaourler (incroyants) en présence des Turcs, alors qu'ils utilisaient toujours pour les Mahométans les noms de agha, bacham, effendem, sultan, hadj, etc. Mais si aucun Mahométan n'était présent, alors ils faisaient preuve d'un orgueil insupportable, et les noms de cafre, kopek, et autres, étaient les plus modérés dont ils affublaient les Turcs. La plupart des Arméniens que j'ai connus m'ont paru sérieux et sincères. Ils faisaient montre face aux Turcs d'une dignité certaine, et il m'a semblé que les Turcs se montraient aussi envers eux plus courtois qu'avec les Grecs. Ils devaient bien sûr entendre sans répit le nom de giaour, mais ils ne plaisantaient pas sur ce point et se nommaient entre eux Chrétiens. J'ai souvent entendu des petites gens mahométanes les appeler par ce nom.

Il semble que les Juifs soient au moins aussi méprisés par les Mahométans au Yémen et à Chiraz que par les Chrétiens en Europe. Il y a très peu de Juifs au royaume d'Oman et je n'ai parlé qu'à leur chef (cheikh). Celui-là était très content des Mahométans locaux, il s'habillait même comme un Mahométan. On trouve un grand nombre de Juifs dans les villes turques. Ils y pratiquent, comme dans les autres pays de l'Orient, divers métiers, et semblent sur ce point disposer de plus de liberté que leurs frères en Europe, où ils sont souvent empêchés par les corporations de gagner honorablement leur pain par leur travail manuel. Mais comme ils doivent porter un signe particulier à cause de la capitation, qui permet de les reconnaître, et sont également très méprisés non seulement par la populace turque mais aussi par la populace chrétienne, ils sont les plus craintifs des sujets du sultan. Je n'ai pas entendu les Arabes les nommer autrement que yahoudi. La populace turque au contraire, et à son exemple très souvent les Chrétiens, 
les nomment $t c h e f o u d^{57}$, un nom qui est encore bien plus méprisant que giaour. Pourtant, on trouve aussi parmi eux de grands négociants et changeurs, qui, pour leur argent, sont bien reçus du gouvernement turc, et ont ainsi l'occasion de venger leurs frères qui auraient été insultés. Les Juifs orientaux se trouvent très bien en Égypte; en effet, ils ont su se rendre si nécessaires dans ce pays qu'ils ont affermé les douanes depuis de nombreuses années, et se sont en particulier acquis ainsi auprès des Cairotes distingués une grande considération.

On ne peut pas vraiment affirmer que les Mahométans tiennent absolument les adeptes d'autres religions pour impurs. Bien qu'un Arabe qui n'avait jamais vu d'Européens, ainsi que quelques clercs hypocrites, n'aient pas voulu manger avec moi parce que j'étais Chrétien, j'ai très souvent mangé avec des Sunnites, et en retour eux avec moi. Bien que les Brahmanes soient leurs prêtres communs, les différentes sectes de païens en Inde ne mangent même pas entre elles, et encore moins avec les membres d'autres religions. Les Persans ne mangent pas non plus du même plat avec les païens, les Juifs et les Chrétiens, même pas avec les Sunnites quoiqu'ils soient Mahométans. Cela est également connu des Juifs. De cette conduite des Indiens, Persans et Juifs, les Sunnites tirent la conclusion que ces nations tiennent toutes les autres pour impures. Du fait que les Chrétiens se montrent immédiatement tout disposés à manger avec eux, cela constitue vraisemblablement une des principales raisons pour lesquelles ils leur témoignent une bien plus grande confiance qu'à toutes les autres nations mentionnées. »

\section{e) 364 (pèlerinage à La Mecque)}

«Les pèlerins, lorsqu'ils viennent pour la première fois à la Kaaba, passent habituellement par Bab al-Salam et sortent par Bab al-Umra.

Il s'agit là du lieu saint au sens étroit (Masjid al-haram). Le territoire sacré de la ville s'étend au-delà, et il est repéré sur les routes d'accès par certains signes (Mikat al-ihram). C'est ici que les pèlerins accomplissant leur premier pèlerinage doivent se mettre le ihram ou ahram* , ce qui signifie qu'ils doivent, tout comme les Arabes vivant ici, se vêtir avec la plus grande humilité, à savoir ceindre un linge autour des hanches [n. : dans les bains, où l'on porte aussi un tel linge autour des hanches, on l'appelle également ihram. Ce mot ne peut donc pas, comme on peut le lire couramment dans les traductions européennes, être traduit par "l'habit sacré"], et un autre sur l'épaule. Ils doivent également aller tête nue, peut-être parce que les Bédouins et autres Arabes du commun se laissaient pousser les cheveux du temps de Mahomet et allaient tête nue, comme, vers le Sud, les Arabes de Haïl et ceux de Hachid et Bakil ${ }^{58}$. Les lieux où il faut ceindre

57. Mot, toujours aussi méprisant, encore utilisé aujourd'hui.

58. Il s'agit de confédérations tribales yémenites. 
l'ihram sont: sur la route du Yémen, Yalamlam. Sur la route du Nejd, Qarn. Sur la route d'Irak, Dhat. Sur la route de Médine, Dhu al-Hulaïfa. Sur la route de Damas et du Caire, Juhfa, et seulement pour ceux qui viennent de Suez par mer, Ras Wardan. »

\section{f) 377-379 (tribus juives)}

«Dans la région montagneuse du Hedjaz, on trouve aussi de nombreuses petites seigneuries indépendantes. (...) Je n'ai pas reçu d'autres informations sur les seigneuries indépendantes de cette région, seulement sur le district de Khaybar*, au nord-est de Médine, qui jusqu'à ce jour est habité par des Juifs indépendants, qui comme les autres Arabes vivent sous leurs propres cheikhs. Une tribu de ces Juifs arabes serait celle des Bani Missead*59 une autre celle des Bani Chahan*, une troisième celle des Bani Anaza*. Le nom des Bani Khaybar est encore si haï des Mahométans du nord qu'il est presque impossible de plus injurier quelqu'un qu'en l'appelant descendant des Bani Khaybar. C'est pourquoi ils disent aussi que leurs caravanes dans le Hedjaz sont pillées par les Bani Khaybar. Ce faisant ils font trop d'honneur à ces Juifs ; en effet, lors du dernier pillage, les meneurs étaient les cheikhs des tribus Harb du Hedjaz et Anaza du Nejd, alors que, selon les dires de Mahométans dignes de foi, les Juifs de Khaybar n'avaient contribué à cette armée arabe qu'avec peu d'auxiliaires ${ }^{60}$.

Il semble que les Juifs de Khaybar n'ont absolument aucune communauté avec les Juifs qui habitent dans les villes situées à la frontière de l'Arabie. En tout cas, ceux d'Alep et de Damas ne voulaient avoir entendu quoi que ce soit à leur sujet. Comme je m'appuyais sur le témoignage de si nombreux Mahométans, ils me répondaient que ceux-là ne pouvaient en aucun cas se présenter chez eux car ils n'observaient pas la loi à leur manière à eux. Les Juifs de Khaybar sont peut-être des Karaïtes ${ }^{61}$ [n. : On pourrait également tirer cette conclusion de la remarque du Chérif Idrissi dans sa Geog. Nub., p. 110, selon laquelle: "Khaybar est une petite ville fortifiée, presque un fort, riche en palmiers et en champs labourables. Selon les ouvrages des

\section{S'agirait-il des Bani Musayad?}

60. À propos du Hedjaz, $\mathrm{CN}$ évoque des tribus juives indépendantes vivant au N.O. de Médine, dont celles des Bani Anaza et des Bani Khaybar. Le fait que CN rapporte l'existence de Juifs au Hedjaz au XVII ${ }^{\mathrm{e}}$ s. paraît surprenant, car, selon la tradition canonique islamique, ils auraient tous été expulsés au temps du Prophète ou peu après. Si c'était une réalité, cela constituerait une découverte majeure. Noter cependant que l'appellation Bani Anaza semble impliquer que ces Juifs vivaient comme clients de grandes tribus arabes plutôt qu'en tribus entièrement autonomes.

61. Mouvement attaché exclusivement à l'Écriture, né à Bagdad au $\mathrm{VIII}^{\mathrm{e}}$ siècle, qui a connu un grand essor jusqu'en Pologne. 
Musulmans, c'était là que résidaient les Karaïtes" (trad. du latin). La résidence de ces Juifs, à laquelle on ne peut parvenir, spécialement de l'Est et du Nord, qu'à travers de vastes zones désertiques, a peut-être donné naissance à la légende du fleuve du Sabbat; en effet, les Juifs, comme on le sait, ne voyagent pas le jour du Sabbat. Or les caravanes, avec lesquelles ils sont contraints de voyager en Orient, ne s'arrêteraient pas pour eux. Ne pouvant voyager seuls en sécurité dans ces grands déserts, ils ne peuvent donc, à cause de leur Sabbat, entreprendre aucun voyage vers Khaybar. Barthema ${ }^{62}$ mentionne également des Juifs indépendants dans la région de Médine] ; car on ne trouve pas des Karaïtes seulement en Pologne, à Constantinople et au Caire, mais aussi dans quelques villages au bord de l'Euphrate, et tous ceux qui se reconnaissent dans cette secte sont plus haïs chez les autres Juifs, les Pharisiens, que les Mahométans et les Chrétiens.

Le nom de la tribu Anyze ressemble beaucoup au nom Hanassi, dont Benjamin Tudela faisait déjà état il y a près de 600 ans [n. : Itinerarium Benjamini Tudelensis ex versione Benedicti Ariae Montani, p. 75, 76, 77]. De même avec les Bani Anaza, tribu qui a déjà causé beaucoup d'ennuis à Mahomet et aux premiers califes. Cette famille juive aurait donc vraisemblablement régné plus de 1000 ans déjà. »

\section{REISEBESCHREIBUNG (1774 ET 1778)}

\section{a) t. I, 39-41 (traversée Constantinople-Alexandrie en sept. 1761)}

«Le capitaine, son secrétaire et ses timoniers parlaient assez bien l'italien. Le secrétaire n'était pas seulement allé à Venise et dans d'autres ports italiens, il avait même été une fois jusqu'à Vienne. Les Catholiques lui avaient raconté sur les autres Chrétiens des absurdités aussi grosses que celles que racontent les Sunnites sur les autres sectes mahométanes. Je lui demandai un jour s'il y avait encore des païens dans les pays du sultan ? et il me répondit: de ceux-là, il y en a encore beaucoup en Allemagne et Hongrie, où ils s'appellent Luthériens, ils ne savent rien de Dieu et de ses prophètes, etc. Dans les discussions sur la religion, il se révélait être un vrai Mahométan. L'un de nous voulut le convaincre de la vérité de la religion chrétienne. Le secrétaire se leva immédiatement et dit que ceux qui croyaient à d'autres dieux que Dieu étaient des bœufs et des ânes, et sortit aussitôt. Le brave homme nous rappelait ainsi qu' on devait laisser chacun croire

62. «Varthema », Ludovico de Varthema Itinerario ne la Egypta, ne la Syria..., Venise 1517 (éd. allemande Francfort/Main 1548 et Leipzig 1608) ; une nouvelle traduction française Voyage de Ludovico di Varthema... a été publiée à Paris en 2004. 
que sa religion était la meilleure, aussi longtemps qu'il n'en doutait pas luimême. Je ne pensais pas qu'il était de ma vocation de faire du prosélytisme. Par la suite, lorsque je m'informais auprès de Mahométans raisonnables des principes de leur religion, je leur faisais part de différents éléments sur le christianisme, sans affirmer qu'il était meilleur que les enseignements contenus dans le Coran, et personne ne s'en est jamais offusqué.

Ledit secrétaire remplissait à bord les fonctions d'imam. Après que les Mahométans se sont préparés pour la prière, c'est-à-dire ont fait leurs ablutions selon certaines règles, l'imam étend son tapis par terre devant lui, de telle manière qu'il ait le visage tourné vers La Mecque. Tous les autres, gens de qualité et gens de peu côte à côte, posent leurs tapis ou des vêtements derrière lui, si possible de façon à voir ses mouvements sans quitter du regard la direction de La Mecque. Et lorsque l'imam au début de la prière place ses pouces derrière les oreilles, pour signifier qu'il écarte de ses pensées toutes choses profanes et ne les dirige plus que vers Dieu, tous ceux qui prient avec lui font de même. S'il se jette à genoux, et met son front au sol, les autres en font autant. Si l'imam au milieu du murmure de la prière crie : Allah akbar (Dieu est grand!), tous le répètent également. En bref, chez les Mahométans, l'imam est dans une assemblée la personne que tous suivent dans la prière. Comme j'étais depuis peu chez les Mahométans, je craignais provoquer un éclat si je restais lors de leur prière. Or ils n'ont honte ni de leur humilité ni de leurs cérémonies lorsqu'ils en appellent à Dieu. Et ne se laissent aucunement troubler dans leur recueillement par la présence d'adeptes d'autres religions. Plus tard, alors que je me trouvais dans la maison du gouverneur de Suez à l'arrivée de l'imam et que tous se préparaient à la prière, je voulus m'en aller, et c'est le gouverneur luimême qui me dit que je pouvais rester. Seule la populace mahométane n'accepte guère un Chrétien dans une mosquée, spécialement au moment de la prière. On voit très souvent des Mahométans isolés prier. Ils ne vont pas toujours à la mosquée, ou à une assemblée avec présence d'un imam, mais prient là où ils se trouvent au moment prévu, même si cela est sur la voie publique. C'est ainsi que sur notre navire l'un ou l'autre priait aussi lorsqu'il avait le temps et la dévotion. Seule la prière du soir, soit aussitôt après le coucher du soleil, avait lieu en commun et suivant tout un cérémonial. À la fin de celle-ci, ils criaient tous à pleine gorge : que Dieu nous accorde un voyage heureux. »

\section{b) t. I, 267-268 (port de l'ihram)}

«Tous les Mahométans qui vont à La Mecque pour la première fois doivent à certains endroits, pour autant que leur état de santé le permette, ceindre l'ihram, comme cela est décrit dans Beschr. Arab., 364.

Ceux qui viennent de Suez par mer y sont tenus dès qu'ils ont atteint les collines de Wardan, que nous avons passées aujourd'hui. Ihram signifie 
au fond un linge noué autour des hanches comme on l'utilise dans les bains, et un pèlerin nouveau doit se contenter de cette seule pièce de vêtement jusqu'à ce qu'il ait visité la Kaaba à La Mecque. Il peut cependant porter encore un autre linge sur l'épaule, comme le Turc qu'a dessiné M. Baurenfeind sur la planche LIV. De nombreux pèlerins sur notre navire qui n'étaient jamais allés à La Mecque gardaient pourtant leurs vêtements, parce qu'ils n'étaient pas bien, ou le prétendaient. En revanche, d'autres Mahométans pieux ceignaient l'ihram alors qu'ils n'y étaient pas tenus par la loi puisqu'ils avaient déjà fait le pèlerinage auparavant. Ce qui explique que nous ayons vu le soir sur notre navire un grand nombre de personnes dans une tenue toute différente de celle du matin. »

\section{c) t. I, 438-440 (l'ermite Chadhili à Mokha)}

«Étant donné que, à Mokha, j’ai plus recherché la compagnie des Anglais que celle des Arabes, je ne me suis pas soucié de m'informer avec précision de l'ancienneté de cette ville. Il est cependant certain que Mokha fait partie des villes les plus nouvelles de la Tihama et n'a pas plus de 400 ans. C'est à peu près à cette époque qu'a vécu un ermite célèbre, le cheikh Chadhili, qui a toujours été tenu pour le fondateur de cette ville. Ce cheikh s'était acquis un si grand nom par son mode de vie solitaire et pieux que, de son vivant déjà, on venait de contrées éloignées pour entendre son enseignement. On m'a raconté à son sujet ce qui suit. Un jour, un navire en provenance d'Inde et à destination de Djedda avait jeté l'ancre dans la région et lorsque des membres de l'équipage virent une petite hutte dans ce coin désertique, la curiosité les poussa à descendre à terre. Le cheikh reçut ses hôtes de la manière la plus amicale et leur servit du café, une boisson qu'il affectionnait et à laquelle il attribuait d'excellentes qualités. Les Indiens, auxquels le café était encore totalement inconnu, tenaient cette boisson chaude pour un médicament. Ils pensaient que le commerçant qui était à bord, malade à ce moment-là, pourrait peut-être guérir s'il en absorbait, et le cheikh Chadhili assura que non seulement le malade recouvrerait la santé par sa prière et la boisson, mais qu'il lui procurerait un grand profit s'il débarquait à terre ses marchandises. Il prophétisa en outre que, en ce même lieu, existerait un jour une place commerciale réputée et qu'à l'avenir les Indiens y vendraient une grande partie de leurs marchandises. Ces paroles parurent si singulières au marchand qu'il eut envie le lendemain de se faire conduire à terre pour rencontrer cet homme extraordinaire et parler avec lui. Il se trouvait que ce même jour un grand nombre d'Arabes devait rendre visite à l'ermite pour écouter ses sermons. Le marchand but du café que lui avait préparé le cheikh Chadhili et se sentit mieux. Parmi les Arabes qui rendaient visite au cheikh se trouvaient de nombreux marchands, qui achetèrent toute la cargaison. Le marchand rentra donc en Inde particulièrement heureux, et la grande sainteté du cheikh se répandit de plus en 
plus. Plusieurs huttes furent construites autour de celle de Chadhili. Le nombre des navires qui faisaient relâche ici crut avec le nombre des commerçants qui descendaient à terre : c'est ainsi qu'est né d'abord le village, ensuite le centre commercial de Mokha. Sur la tombe du cheikh Chadhili, maintenant en dehors de la ville, se trouve une grande mosquée qui porte son nom. Le puits, dont l'eau est bue par tous les pauvres gens qui ne peuvent s'offrir une meilleure qualité, s'appelle Chadhili. Une des portes de la ville porte son nom. Ses descendants sont encore honorés grâce à lui, et appelés cheikhs. L'homme de la rue à Mokha jure chaque jour par son nom : bref, le nom Chadhili ne sera pas oublié tant que Mokha vivra. Un marchand de La Mecque que j'ai beaucoup fréquenté à Bombay m'a fait au sujet de cette sorte de saints une remarque que je n'attendais pas d'un Mahométan. La foule, dit-il, veut toujours avoir quelque chose de sensible qu'elle puisse honorer, et craindre. C'est ainsi p. e. qu'à La Mecque et à Médine tout est affirmé au nom de Mahomet alors qu'on devrait se rappeler le nom de Dieu. À Mokha je ne crois pas celui qui m'assure de quelque chose au nom de Dieu ; je pourrai au contraire me reposer sur lui s'il jure par le nom de Chadhili, dont il a la mosquée et la tombe devant les yeux. J'ai moi-même remarqué que l'homme de la rue à Djedda s'appuie sur le nom de Mahomet, à Mokha sur celui de Chadhili, à Meched Ali ${ }^{63}$ sur celui d'Ali et à Meched Hussein ${ }^{64}$ sur celui d'Hussein.

Chadhili n'est pas simplement le patron de la ville de Mokha, il est aussi le patron de tous les cafetiers mahométans adeptes de la secte sunnite, et on raconte qu'ils l'évoquent tous les matins dans leur fatiha (prière). Ils ne font d'ailleurs pas appel à lui, mais remercient Dieu d'avoir enseigné à l'humanité l'usage du café par l'intermédiaire du cheikh Chadhili, et le prient d'accorder ses grâces à Chadhili et à ses descendants [n. : A Basra et Bagdad, et probablement dans l'ensemble des villes des Sunnites, tous les artisans honorent leurs saints particuliers. P.e. Salman Pak, qui aurait été un ami de Mahomet et son barbier (Allgemeine Welthistorie der neuen Zeiten, première partie, parag. 71) ${ }^{65}$, est le patron des barbiers, et ces derniers se rendent un certain jour chaque année sur son tombeau à Al-Madeien, ville jadis célèbre dont on voit maintenant les ruines à un mille de Bagdad. Daoud ou David est le patron des forgerons, car, selon le $21^{\mathrm{e}}$ chapitre du Coran $^{66}$, il a d'abord fabriqué des cuirasses. Nabi Chouaïb est le patron des tisserands. Ibrahim al-Khalil est le patron des maçons et des cuisiniers. Nabi Idriss est le patron des tailleurs. Habib est le patron des ébénistes, il

63. Aujourd'hui Nadjaf.

64. Aujourd'hui Kerbela/Karbala.

65. En français Histoire mondiale générale des temps nouveaux. Il s'agit d'un ouvrage publié à Halle de 1759 à 1765 sous la direction de Johann Salomo Semler, en fait une traduction de l'anglais.

66. Sourate XXI, vt. 80. 
est enterré dans la région de Bagdad. Nabi Gorgis est le patron des chaudronniers en cuivre ${ }^{67}$. Mohammad ibn al-Yamani est le patron des cordonniers. Mohammad al-Jaouad, ou bien comme disait un autre, Jamard, est le patron des tueurs ${ }^{68}$, etc.]. »

\section{d) t. II, 177-179 (préparatifs pour le pèlerinage à Meched Ali)}

« Ce jour-là nous rencontrâmes une caravane, 30 à 40 Arabes de Bahrein et al-Qatif, qui tous voulaient aller à Meched pour rendre visite au tombeau d'Ali ibn Musa, un des 12 imams des Chiites. Quelques femmes arabes se trouvaient également parmi eux. Tout Chiite, auquel sa santé, sa fortune et ses affaires le permettent, est, selon la loi mahométane, tenu, comme tout Sunnite d'ailleurs, d'aller une fois à La Mecque. Mais comme cela est non seulement dangereux et coûteux, mais aussi désagréable car au cours du voyage les Sunnites les traitent avec mépris comme hérétiques, beaucoup se contentent de rendre visite à la tombe d'un ou plusieurs de leurs imams. Si quelqu'un a de la fortune et ne fait pas lui-même le voyage à La Mecque ou aux tombeaux des imams, on prélèvera à sa mort sur la succession ce qu'il faut pour qu'un autre puisse faire le voyage à la place du défunt. C'est pourquoi l'on trouve tant de pèlerins professionnels, qui font le voyage pour une petite somme, et cependant y trouvent leur bénéfice. Il y avait trois chemineaux de ce genre-là dans notre propre caravane, originaires de Bahrein et al-Hassa, l'un d'eux avait déjà fait 9 voyages pour 9 défunts différents. Ceux qui venaient de Bahrein avaient aussi en majorité l'air d'être des pèlerins loués. Seuls quelques-uns avaient des ânes, les autres allaient à pied. Ils étaient extrêmement mal vêtus, et chacun avait sur le dos tout son bagage, à savoir un baluchon avec du pain et des dattes séchées, et un petit récipient en cuivre, dont ils ont besoin pour se laver. Même en Arabie, je n'ai jamais vu une caravane à l'allure aussi misérable. La rencontre inattendue entre ces Arabes en pays étranger m'a donné beaucoup de divertissement. Ils s'embrassaient bien quatre fois sur les deux joues l'un après l'autre, et la main aussi souvent, et demandaient à chaque fois comment ils avaient vécu. Ceux-là, qui venaient de Bahrein, interrogeaient nos Arabes sur la route pour Meched. Ceux-ci, les nôtres, leur demandaient la route pour Buchahr ${ }^{69}$, et les deux côtés assuraient qu'il n'existait aucun pays au monde où l'on pouvait voyager en aussi grande sécurité qu'en Perse. Il est certain que, dans leur tenue, ils n'avaient rien à craindre des brigands. Les questions étaient ensuite : combien coûte une livre de pain, de riz ou de beurre dans les régions d'où ils venaient ? Les deux partis, venus peut-être

67. On dirait en français d'aujourd'hui « dinandiers ».

68. Il s'agit bien sûr de ceux qui travaillent dans les abattoirs.

69. Sur la côte iranienne non loin de l'île de Kharg, «Abuschahhr s(ive) Busheer» sur la carte du sinus persicus, pl. XIX de Beschr. Arab. 
tous deux d'une région aride, se croyaient transportés dans un paradis ; je ne m'étonnais plus du tout que ces pauvres diables se rendent si volontiers à Meched comme pèlerins loués. À la fin on parla encore de questions de la maison, car certains voulaient avoir des nouvelles, et d'autres en faire donner, et cette rencontre se termina par de bons souhaits exprimés avec ardeur. Il était affligeant de rencontrer en Perse, 18 ans après la mort de Nadir Chah, tant d'hommes borgnes, qui avaient perdu un œil par la fureur du tyran mentionné. Quelques-uns de ces malheureux se trouvaient également parmi les Arabes de Bahrein. J'ai encore vu des preuves de sa cruauté jusqu'à Sourat, Mascate, Bassora et Bagdad, aussi bien sur des marchands arméniens que mahométans, qui avaient ensuite quitté leur patrie. »

\section{e) t. II, 198-201 «Observations sur Kharg ${ }^{70}$ »}

«La différence la plus claire entre les Sunnites et les Chiites consiste, comme on le sait, dans le fait que les premiers considèrent avec une complète indifférence le fait de savoir si la famille du Prophète est arrivée au gouvernement et s'y est maintenue, ou non. Ils soutiennent que la volonté de Dieu a été que Abou Bakr, Omar et Othman aient été reconnus comme califes par les Musulmans, et qu'il n'est pas du tout en leur pouvoir de ne pas reconnaître que ces amis de Mahomet, et non immédiatement son gendre et ensuite les enfants de ce dernier, soient arrivés au gouvernement. Mais les Chiites maudissent les trois premiers califes mentionnés ci-dessus parce qu'ils se sont emparés du gouvernement avant Ali : et comme Hussein a été assassiné au cours d'une bataille par les troupes de Yazid, l'un des califes suivants, parce qu'il ne voulait pas se soumettre mais devenir luimême calife, ils célèbrent toujours chaque année en mémoire de cette affaire une fête qui dure dix jours. En Perse, où leur secte domine, ils peuvent parfois devenir à cette occasion si ardents qu'ils se font un mérite de pouvoir massacrer en ce temps-là un Sunnite, c'est-à-dire un Mahométan qui peut être indifférent à cette question si importante de la succession des premiers califes. Il est donc conseillé à tous les adeptes de religions différentes de ne pas se montrer dans la rue pendant cette fête. Ils ont également liberté de religion à Kharg, mais ne peuvent faire preuve d'un zèle aussi outrancier ; en effet, le nombre des Sunnites sur l'île est aussi grand que le leur, et aussi parce qu'ils doivent craindre les Hollandais. Le gouverneur avait interdit que pendant cette fête on pleure et hurle si fort que les adeptes d'autres religions en soient alarmés. Les 9 premiers jours, ils organisaient leurs processions et leurs autres cérémonies hors de la ville. Comme je n'avais pas encore vu ces festivités des Chiites, il leur fut permis, à cause de

70. Il s'agit d'une ville sur une île éponyme au nord du Golfe Persique, Kharg (sur la carte sus-évoquée, CN indique «Charedsj s(ive) Karek»), devenue de nos jours un grand port de chargement de pétrole brut. 
moi $^{71}$, de venir en procession dans la ville le dernier jour, le 29 juin, et d'y jouer la tragédie sur la grand-place. C'est là que se rassemblèrent presque tous les Mahométans qui habitaient à Kharg. Mais à chacun on pouvait voir s'il était Sunnite ou Chiite. Certes beaucoup des premiers semblaient très émus par cette présentation du malheureux petit-fils de leur Prophète ; ils restaient en réalité de calmes spectateurs. Les seconds se frappaient la poitrine, ou donnaient d'autres signes pitoyables de leur grande affliction ; beaucoup pleuraient si chaudement que les larmes leur coulaient sur les joues, et tous criaient Hussein! Hussein ! Ceux d'entre eux qui devaient jouer l'armée du calife Yazid sous le commandement du général Omar ibn Saïd couraient avec les épées nues sur un côté de la place comme s'ils cherchaient l'ennemi. Là-dessus arriva Hussein avec un très petit groupe d'amis, qui bientôt devinrent enragés. Sur leurs visages et dans l'ensemble de leur comportement se lisaient leur grand désespoir et leur détermination à faire payer cher leur mort toute proche ; il semblait que véritablement ils se préparaient à se défendre. L'un d'eux, que l'on me dit s'appeler Qasim, fut jeté à plusieurs reprises bas de la selle. Quand il voulut remonter à cheval, ses filles le prièrent instamment de ne pas reprendre le combat; en même temps elles pleuraient aussi sincèrement que si leur père voulait réellement s'exposer au plus grand danger. Abbas, un frère d'Hussein, auquel les deux bras avaient été coupés lorsqu'il était allé à une source pour y étancher sa soif, était représenté d'une manière relativement réaliste. Il avait les deux bras sur le corps, et les manches de sa tunique pendaient à partir des épaules. Tous ceux qui devaient représenter les personnes de qualité étaient à cheval, et les autres à pied, car on avait sur cette île peu de chevaux et pas du tout de chameaux. Et comme la communauté locale n'est presque composée que de pauvres gens, tous étaient bien mal habillés, mais aussi bien qu'une armée arabe avait pu l'être sur le champ de bataille il y a 1100 ans. La musique militaire que l'on entendait ici se faisait avec de simples cuvettes métalliques que l'on frappait avec application l'une contre l'autre. Joint aux nombreux cris du nom de Hussein, cela donnait bien sûr un bruit vraiment horrible. La petite armée de Hussein fit reculer à plusieurs reprises l'ennemi en plus grand nombre mais au bout du compte, les officiers les uns après les autres et Hussein lui-même furent jetés bas de leurs montures et tous les autres faits prisonniers. À beaucoup d'enfants d'Hussein on accrocha un gros morceau de bois au cou, et un bourreau que l'on avait habillé de façon effrayante fut chargé de les conduire au général ennemi. Quelquesuns de ceux-ci répondirent au vainqueur avec un air de grand défi. L'ordre fut alors donné d'exécuter ces derniers ; mais on apprit ensuite que le bourreau avait enlevé la vie à tous, ce qui rendit le général si ulcéré qu'il le condamna également à mort.

71. CN a été très bien reçu par les Hollandais, il s'agit donc d'une faveur du gouverneur à son égard. 
Le champ de bataille sur lequel Hussein perdit la vie se trouvait, comme on le sait, à Kerbela, à proximité de l'antique Babylone. Yazid, le calife d'alors, résidait à Damas. Il était présent ici de l'autre côté de la place, assis sur un fauteuil européen, avec un derbache (marteau de combat) dans la main. Selon l'histoire mahométane, alors que les très rares survivants de la famille de Hussein étaient conduits devant Yazid, un envoyé de l'empereur de Grèce lui fut également présenté, mais il portait un vêtement européen, sans bas, et sur sa tête chauve un chapeau couvert d'or, à l'évidence une tenue que les Grecs n'avaient jamais portée. Peut-être voulaient-ils ainsi nous complimenter, nous les Européens, pour montrer aux Sunnites que les Chrétiens avaient été des amis de Hussein plus grands et en tout cas plus justes que leurs califes. En effet, alors qu'était conduit devant le calife pour lui être présenté, un fils de Hussein du nom d'Ali, ensuite connu sous le nom de Zayn al-Abidin, qui devait se soumettre ou bien plutôt renier sa foi comme disent les Chiites, faisait une réponse pleine de défi, la vie lui fut accordée deux fois sur la prière de cet envoyé. Conduit pour la troisième fois, et l'envoyé ayant à nouveau demandé sa grâce, le calife fit exécuter l'étranger ; le garçon devait également perdre la vie mais il fut enlevé secrètement. Beaucoup d'autres personnages furent présentés à cette occasion, je n'ai pas enregistré leurs noms et leur histoire.

Je dois encore raconter ce qui suit sur la superstition chez les gens d'ici. Il y a quelques années, un soldat tua son sous-officier, sur quoi on lui coupa une main, et ensuite on le pendit. La main était-elle à peine coupée qu'au plus grand étonnement des Hollandais une foule de femmes se pressa pour avoir un peu du sang versé. Elles se battirent pour le sable imbibé de sang humain, et lorsque le meurtrier pendait à la potence beaucoup de femmes se précipitèrent sous lui, le tout parce qu'elles pensaient que cela les aiderait à être enceintes. »

\section{f) t. II, 254-257 «Observations sur Meched Ali »}

«La ville de Meched Ali* tient son nom d'une mosquée magnifique qui a été construite en hommage à Ali, le quatrième calife des Mahométans, et qui est visitée avec grande dévotion par les Chiites de toutes les régions comme l'est La Mecque par les adeptes de toutes les sectes mahométanes. Les Chiites veulent même aller en pèlerinage encore après leur mort dans cette ville qu'ils tiennent pour sainte ; on apporte ici des morts qui ne viennent pas seulement de Roumaihi ${ }^{72}$, Lemlum ${ }^{73}$, Hilla ${ }^{74}$, Bagdad et d'autres villes voisines, mais aussi de Perse, et même d'Inde. On racontait à Zoubair

72. Sur la rive droite de l'Euphrate, face à Diouaniya (près de l'ancienne Babylone) sur la rive gauche.

73. Sur la rive gauche de l'Euphrate, au S-E de Nadjaf.

74. Sur la rive droite de l'Euphrate, légèrement au sud de Kerbela. 
ou Vieux Bassora qu'on aurait récemment déterré un mort, en terre depuis un an, pour le conduire dans cette ville. Cela rapporte beaucoup. Sur le chemin de Roumaihi à Meched Ali, j'ai vu quatre morts, et d'ici à Hilla j'en ai croisé cinq. Lorsque j'ai demandé si l'on pouvait retenir le chiffre de sept défunts amenés ici de lieux extérieurs chaque jour ${ }^{75}$, on m'a indiqué que cela ne serait pas exagéré. Selon ce calcul, ce seraient donc plus de 2000 morts étrangers qui seraient enterrés ici chaque année. Celui qui paie grassement obtient une tombe près de la mosquée de leur imam. Celui qui paie moyennement peut encore être enterré dans le mur d'enceinte de la ville, et qui ne veut donner que 4 à 8 stuever $^{76}$ n'aura une place qu'à l'extérieur de la ville. Je ne crois pas qu'on enterre à l'intérieur même de la mosquée. On ne trouve pas non plus de sépultures dans les autres mosquées des Mahométans, sinon celle du donateur, et peut-être aussi celle de sa femme et de ses enfants. Au fond, les Mahométans n'aiment pas les cimetières à l'intérieur du mur d'enceinte.

Divers savants sunnites m'ont assuré que l'on ne savait pas avec certitude où Ali, le gendre de leur Prophète, était enterré ; et il n'est certes pas invraisemblable que sa famille ait cherché à dissimuler sa tombe à ses ennemis. Les Chiites montrent pourtant son tombeau dans la mosquée. Ils racontent qu'Ali avait ordonné qu'à sa mort son corps soit accroché à un dromadaire et qu'il soit enterré là où l'animal s'arrêterait après qu'on l'ait chassé de Kufa. Un ordre bizarre de la part d'un homme aussi avisé tel qu'on décrivait Ali. En attendant, l'enterrement supposé a créé l'occasion pour l'édification d'une ville. Celle-ci se trouve dans une zone aussi aride et infertile que Suez et Djedda. Elle n'a aucune ressource en eau. Celle dont on a besoin pour cuire et se laver vient par une conduite souterraine, et la bonne eau potable, on va la chercher avec des ânes à trois heures de chemin. Le sol d'un côté de la ville est si riche en calcaire qu'il suffit de mélanger la poussière avec du fumier séché et de faire brûler l'ensemble pour obtenir une bonne chaux. La chaux étant donc bon marché ici, le bois en revanche très cher, toutes les maisons sont construites en briques cuites posées à la chaux, et toutes voûtées, ce qui leur donne une longue durée de vie. De l'autre côté de la ville, se trouve une grande plaine basse couverte de sel. Les Arabes la nomment al-Buhayr, ou Bahr Nadjaf, et assurent qu'il s'agit du Buhayrat Saoue Sey, qui serait devenu sec à la naissance de Mahomet.

Les habitants de cette ville sont en partie Sunnites, en partie Chiites. Il règne ailleurs qu'ici une telle haine entre les adeptes de ces deux sectes que, lorsqu' un Sunnite se rend en Perse, ou un Chiite en Turquie, il doit faire ses prières à la manière du pays pour ne pas être maltraité par la populace. Ils se supportent relativement bien à Meched Ali et Meched Hussein. Car

75. Sous-entendu : « en moyenne».

76. Petite monnaie hollandaise. 
les Sunnites vivent en grande partie des Chiites, et doivent donc s'accommoder avec eux ; et les Chiites doivent également se tenir tranquilles s'ils ne veulent pas donner au pacha l'occasion de renchérir encore le droit de visiter la tombe de leur premier imam. Chaque année, environ 5000 pèlerins se rendent habituellement sur les tombes d'Ali et d'Hussein. Pour leur dévotion, ils n'ont pas de jours fixés comme les pèlerins à La Mecque. Les Chiites croient cependant que leur prière sera mieux entendue certains mois, en conséquence ils choisissent de préférence le 27 du mois de Rajab, le mois de Ramadan et le 10 du mois de Muharram. On entend rarement ici quelqu'un assurer quelque chose au nom de Dieu, ils jurent tous par le nom d'Ali, à Meched Hussein par le nom d'Hussein et à Mokha par le nom de Chadhili [n. : t. I, 440]. On entend à chaque instant quelqu'un s'écrier dans un soupir recueilli : "Ô toi Ali martyr ! Ô toi Hussein martyr ! Bénie soit votre mémoire!". »

\section{g) t. II, 269-270 «Observations sur Kerbela»}

«Les Sunnites vont aussi dans la mosquée d'Hussein pour y faire leurs dévotions, mais toujours avec leur sérieux habituel. Les Chiites jettent des hauts cris lamentables. J'étais ici juste pour la pleine lune du mois de Rajab, période où des centaines de pèlerins viennent pour passer la nuit entière auprès du tombeau d'Hussein : comme ils n'ont pas de calendrier imprimé et qu'ils sont ainsi dans l'incertitude sur leurs jours de fête, beaucoup restent deux nuits dans la mosquée pour être certains qu'ils n'ont pas manqué le temps fixé. J'ai vu avec un très grand étonnement comment les gens superstitieux baisaient avec dévotion le portail de l'avant-cour, et en plus baisaient ensuite la porte de la mosquée. Dans le temple ils ne doivent pas seulement baiser le sol avec zèle, on m'a assuré que quelques-uns, dans leur affliction sur la mort d'Hussein, frappaient leur tête contre le mur et les grilles en fer. Certains se seraient mis dans une telle rage de dévotion qu'ils se seraient tués près du tombeau de leur grand imam dans l'idée qu'eux aussi seraient considérés comme des martyrs, et ainsi iraient au ciel puisqu'ils avaient sacrifié leur vie pour Hussein. Je dois avouer que je n'ai rien entendu de plus affligeant que la prière des Chiites dans cette mosquée. Les gens criaient et pleurnichaient comme si Hussein leur père venait d'être assassiné le jour même ; et cela n'était pas feint, comme chez les pleureuses qui pleurent un mort pour de l'argent, c'était si sincère que les yeux de ceux qui sortaient de la mosquée étaient tout enflés d'avoir pleuré. Je crois pouvoir dire que j'ai trouvé les Chiites de cette ville beaucoup plus zélés que ceux de Meched Ali. S'ils étaient leurs propres maîtres, aucun Sunnite n'aurait sûrement le droit de se montrer dans cette ville. Mais ils doivent maintenant se tenir tranquilles. Les autorités turques, en raison des grands avantages qu'elles en tirent, leur laissent toute liberté de pratiquer leur culte à leur manière dans tous les lieux jugés saints par eux. Les Sunnites raisonnables ne s'opposent d'ailleurs pas à eux lorsqu'ils 
nomment Hussein imam et martyr. Mais ici ils ne doivent pas maudire les trois premiers califes, et cela représente une dure interdiction pour un Chiite zélé, particulièrement en des endroits aussi saints que Meched Ali et Meched Hussein.

La chose dont il faut ici le plus se garder, les voyageurs chiites en particulier, est la compagnie de janissaires dévoyés qui ont été chassés de Bagdad en partie à cause de leur comportement. Ils cherchent à faire la connaissance de riches Persans. Ils leur dressent un tableau épouvantable du gouvernement turc et des Sunnites, dont les Chiites ne pensent déjà pas trop de bien. Si l'étranger se laisse entraîner, ils lui cherchent bientôt des noises. Ils l'accusent d'avoir dit ceci ou cela contre le gouvernement, et même contre la religion. Ils ont aussitôt des témoins : et si le Persan qui souvent ne comprend ni le turc ni l'arabe ne veut pas être livré aux autorités, il doit payer lourdement. Un de ces individus à la mauvaise réputation, bien vêtu, voulait lier conversation avec moi dans un café. Il pensait que j'étais un marchand arménien. Lorsqu'il découvrit un Européen, il était encore plus réjoui. Il vanta les multiples services dont il avait joui à Alep et Constantinople de la part des Européens, il en nomma même quelquesuns par leur nom, et assura qu'il lui serait très agréable, en un endroit où je devais être totalement étranger et où l'on estimait les Européens aussi peu que les Chrétiens orientaux, s'il pouvait m'obliger en retour. J'avais souvent entendu en Perse de tels compliments sans importance. Mais je n'étais pas habitué à des offres si hâtives de la part d'honnêtes Turcs et Arabes. Je fis donc tout de suite très attention : et lorsque j'appris ensuite avec quel individu j'avais parlé, je décidai d'éviter dorénavant ici toute compagnie.

En passant je veux encore observer que la Kaaba n'est pas chez les Mahométans le seul lieu libre d'accès aux pigeons. Ils sont également aussi peu dérangés dans les mosquées sur les tombes d'Ali et d'Hussein, à la Jami ou mosquée principale de Hilla, cela est le cas dans d'autres villes aussi. »

\section{h) t. II, 270-274 «Différence entre les Sunnites et les Chiites »}

«Comme j'ai souvent mentionné les Chiites, je dois également dire quelque chose de la différence entre leur religion et celle des Sunnites [n. : dans la traduction par Semler de Allgemeine Welthistorie der modernen Zeiten t. I, 538, l'auteur écrit : les Sunnites emploient le mot chiite comme une invective. Les partisans d'Ali se nomment adliya. Je n'ai jamais entendu les adeptes de la secte persane se nommer adliya, et ils ne regardent sûrement pas le mot chiite comme une injure. Pour se moquer, les Turcs appellent les Persans kizilbach ${ }^{77}$ ]. Tout comme ces derniers, ils tiennent le Coran pour

77. Mot turc, au sens propre « tête rouge »; référence à une période $\left(\mathrm{XVI}^{\mathrm{e}} \mathrm{s}.\right)$ de conflits entre Turcs à la coiffe blanche et Persans et Kurdes au couvre-chef rouge. 
leur premier code. Ils affirment également qu'il n'y a qu'un seul Dieu et que Mahomet est son prophète ; ils doivent entretenir la propreté de leur corps, prier cinq fois par jour, faire généreusement l'aumône, jeûner pendant le Ramadan et aller une fois à La Mecque. En revanche ils expliquent divers passages du Coran différemment des Sunnites. Et comme ils se sont séparés de ces derniers sur le fait que la famille de leur prophète commun n'a pas obtenu le califat, ils ont fait de divers compléments visant cette question des points de doctrine dont les Sunnites ne veulent rien entendre. Ce qui ressort le plus est qu'ils maudissent les trois premiers califes, Abou Bakr, Omar et Othman. Voilà ce qui provoque la plus grande haine entre les adeptes des deux sectes. Un Chiite doit ensuite croire aussi aux douze imams, qui auraient dû selon eux régner l'un après l'autre, mais ont été repoussés, et même persécutés, par les califes. Le premier imam est Ali, gendre de Mahomet, mentionné précédemment. A la profession de foi : "Il n'y a qu'un seul Dieu et Mahomet est son prophète", les chiites ont ajouté : "et Ali est son vicaire (wali)". Plusieurs auteurs européens ont prétendu qu'ils donnaient la préférence à Ali sur Mahomet. Mais ils ne le placent pas si haut, même s'ils rendent à sa mémoire des honneurs extraordinaires.

Le second imam est Hassan, le fils aîné d'Ali et de Fatima. Il est enterré à La Mecque. Le troisième, qui vient d'être mentionné, est Hussein, son frère. Le quatrième imam s'appelle Ali, le cinquième Mohammad surnommé al-Baqir, et le sixième Jaafar. Ces trois-là sont enterrés à Médine. Le septième imam est Musa al-Kazim, dont la tombe sera mentionnée près de Bagdad. Le huitième imam, Ali al-Rida, est enterré à Meched au Khorassan. Mohammad al-Jaouad, le neuvième imam des Chiites, est près de son grandpère Moussa dans une mosquée du Vieux Bagdad. Ali al-Hadi et Hassan al-Askari sont considérés comme les $10^{\mathrm{e}}$ et $11^{\mathrm{e}}$ imams. Leurs tombes sont montrées à Samurra ou Samarra, une ville sur le Tigre, au nord de Bagdad. Le douzième imam s'appelait Mohammad. Tous, à partir de Hussein, le troisième, jusqu'au dernier, se succèdent de père en fils. Mohammad, le dernier imam, a été persécuté par les califes au point qu'il ne pouvait presque jamais se faire voir en public. On sait cependant qu'il a vécu la plus grande partie de sa vie dans une cave profonde à Samara, et c'est là que l'on montre sa tombe. Les Chiites croient pourtant que Dieu l'a fait disparaître vivant de la terre et qu'il reviendra peu avant la fin du monde sous le nom de Mahdi en convertissant tous les hommes à la secte chiite. La mosquée près de Kufa évoquée p. 264, que l'on appelle Sahib Zaman Mahdi, a probablement été construite en l'honneur de cet imam.

Les tombes des premier, troisième, septième, huitième et neuvième imams sont les plus visitées par les Chiites, d'autant qu'elles sont les plus proches. Quelques-uns vont aussi en pèlerinage à Samara. Mais aucun ne peut se prévaloir à bon droit du titre de hadj, sauf s'il est allé à la Kaaba à La Mecque. Les tombes des chuhada ${ }^{78}$ ou amis de Mahomet, qui, selon

78. «Martyrs». 
les Chiites, sont morts en martyrs, ne sont visitées qu'occasionnellement. Il est rare en outre, tant chez les Sunnites que chez les Chiites, de trouver un village qui ne puisse pas présenter le tombeau d'un prétendu martyr. Ceux-là ne sont guère respectés par les Mahométans venant de l'extérieur autrement que par une petite prière en passant, sans se soucier le moins du monde du nom du saint.

Les Sunnites sont en tout cas très attentifs à respecter l'heure fixée pour la prière. À savoir la prière de midi entre 12 heures et environ 3 heures de l'après-midi, la prière de l'après-midi entre 3 heures et le coucher du soleil, etc. Lorsqu'ils ont laissé passer l'heure fixée, ils ne croient pas que Dieu se satisfasse si sa prière est rattrapée. Certains des Chiites (les Jaafariens peut-être) avec lesquels j'ai voyagé en Perse se facilitaient la vie ; ils priaient donc le soir pour toute la journée. Ces gens-là ne priaient pas, tant s'en faut, avec la dévotion des Sunnites. J'ai souvent vu l'un d'eux s'arrêter au milieu de sa prière pour écouter ce qui se disait, et participer lui-même à la conversation. Ils se lavent toutefois également avant la prière, et étendent un tapis, ou s'ils en manquent, leur manteau, pour ne pas se salir lors de leurs nombreux agenouillements. Et pour rendre leur prière encore plus vigoureuse ils placent, à l'endroit qu'ils touchent de leur front lorsqu'ils s'agenouillent, un macaron ${ }^{79}$ de la terre prétendue sacrée sur laquelle Hussein a été tué ; car ainsi leur prière sera considérée comme s'ils l'avaient faite sur la tombe même de leur grand imam. Après leur prière ordinaire, ils sortent de leur poche un chapelet, fait avec cette même terre, et répètent ensuite certaines paroles de très nombreuses fois jusqu'à achèvement de la prière. Pour finir ils se peignent la barbe.

Les macarons et chapelets en argile évoqués, rapidement usés par l'usage fréquent, et de ce fait, étonnamment, très recherchés, sont façonnés dans une fabrique à Meched Hussein appartenant depuis longtemps à une famille qui se compte dans la lignée des Sayeds ou descendants de Mahomet et professe la foi chiite. Pour ce privilège elle doit payer chaque année au pacha de Bagdad une taxe considérable. Les objets sacrés sont vendus dans une petite construction attenante à la mosquée de l'imam. Je m'en suis fait acheter un lot par mon mollah et j'ai dessiné en D et E sur la planche XLII deux des petits gâteaux de formes et tailles différentes qu'il m'avait apportés : on peut ainsi voir qu'ils ont de jolies formes découpées. J'ai aussi acheté ici un rouleau de papier de 6 pieds 3 pouces de long et 8 pouces de large, avec des représentations de la Kaaba, du tombeau de Mahomet, des tombes des principaux imams et des objets les plus remarquables que l'on montre au pèlerin en ces lieux. Tout cela très mal dessiné et recouvert de couleurs où l'on n'a pas économisé l'argent et l'or. L'animal al-Bouraq*, sur lequel Mahomet a voyagé au ciel, un chameau qui porte l'étoffe précieuse que

79. CN utilise le mot Kuchen, littéralement « gâteau » ou « macaron » pour un petit objet rond peu épais. 
l'on envoie chaque année du Caire à La Mecque, un lion (censé représenter Ali), le célèbre cheval bigarré d'Ali, Douldoul*, son fidèle esclave Ghanbar*, sa célèbre épée Dhoulfiqar*, et le sceau prophétique dont Mahomet devait avoir la marque sur le dos, tout cela est figuré sur ce papier. Mes lecteurs ne me seraient peut-être pas très reconnaissants si je faisais graver sur cuivre tout le dessin. Mais comme il est souvent question de l'épée Dhoulfiqar dans l'histoire arabe, je l'ai reproduite en F. Elle a une forme particulière et elle est d'une taille extraordinaire. En effet, un homme aussi extraordinairement célèbre et fort que l'était Ali se devait d'avoir une épée particulière d'une taille extraordinaire. Par rapport aux autres dessins, celle qui est dans la reproduction a une longueur d'environ 6 pieds $1 / 2$. Les Européens trouveront sa reproduction bizarre. Si au contraire on part de l'hypothèse qu'une épée à deux lames est peut-être attribuée à cet Ali et si l'on sait que les Mahométans d'aujourd'hui ne connaissent que le sabre, on ne peut en vouloir beaucoup aux peintres orientaux de reproduire Dhoulfiqar comme une épée à deux lames. De même, les peintres européens ne figurentils pas souvent de manière spéciale des objets orientaux qu'ils n'ont jamais vus par eux-mêmes?

Sur cette même planche, on peut voir en G un dessin du sceau prophétique avec lequel Mahomet aurait été en quelque sorte marqué au fer rouge. Il est ici couvert d'une inscription arabe ; un clerc sunnite m'a cependant assuré que les savants ne sont encore pas du tout du même avis sur la nature de ce sceau. Il aurait disposé d'une information selon laquelle Mahomet aurait eu là deux petits yeux avec lesquels il aurait pu voir à travers ses vêtements tout ce qui se passait derrière lui. L'animal al-Bouraq est représenté sur ledit papier comme un cheval sellé qui a une tête de femme à longs cheveux, deux petites ailes et une large queue qui remonte. »

\section{i) t. II, 274-286 "Modification de la religion des Chiites sous le gouvernement de Nadir Chah ${ }^{80}$}

« La secte chiite, qui domine en Perse depuis plus de 200 ans déjà et qui s'est étendue au-delà des frontières de ce royaume, était il y a quelques années en grand danger d'être complètement anéantie. Celui qui voulait accomplir cette grande tâche fut Nadir Chah. C'est peut-être par orgueil qu'il voulait acquérir le prestige d'avoir fondé une nouvelle secte ; ou seraitce qu'il avait prévu que ses descendants ne l'égaleraient pas en bravoure et pensé alors que la nouvelle secte pourrait maintenir sa famille sur le trône persan. Le Chah Ismail avait jadis réussi cela. Toutefois Nadir était trop

80. Cette section, qui suit immédiatement la précédente, évoque des événements qui ont eu lieu dans la première moitié du XVIII ${ }^{\mathrm{e}}$ siècle : Nadir Chah est mort en 1747, soit 14 ans seulement avant l'arrivée de CN à Constantinople. 
peu au fait du Coran et de ses divers commentaires. Bien qu'il ait montré une bravoure et une expérience miraculeuses du monde, et conquis non seulement la Perse entière mais aussi l'Inde, les qualités les plus importantes d'un fondateur de secte lui manquaient tout de même, et il a ainsi été la source d'infiniment plus de dommages que de profits. Avant de m'étendre sur cette entreprise du héros persan, il est toutefois nécessaire d'informer plus précisément mes lecteurs sur son origine et sa personne.

La famille de Nadir s'appelait Kirklou, et était une tribu des Afchars, une ethnie turkmène qui avait jadis habité le Turkestan, puis comme tant d'autres tribus turkmènes, kurdes et arabes, s'était établie en Perse. Il était donc un noble turkmène né en Perse, et non un Hollandais comme on l'a raconté en Europe [Histoire de Thamas Kuli Kan, Sophi de Perse] ${ }^{81}$; en considération de sa naissance, il peut en somme être comparé à peu près à un petit cheikh arabe dont la famille s'est mise sous la protection d'une grande tribu [n. : Beschr. Arab., 793] ${ }^{82}$. Il a su cependant utiliser à son avantage les troubles qui régnaient en Perse. L'empire presque tout entier s'était soulevé contre le chah, et particulièrement dans la province éloignée de Khorassan où de nombreux seigneurs s'étaient révoltés. Au début, Nadir tenta, comme d'autres, avec l'aide de quelques gens de devenir le protecteur d'un petit nombre de villages ; comme il s'était procuré de nouveaux fonds par des taxations abusives et des pillages, il recruta plus de gens et chassa d'autres risque-tout qui, comme lui, s'étaient rebellés comme protecteurs de villages : s'il avait un voisin plus fort que lui, il recherchait son amitié en lui promettant de lui prêter aide contre un encore plus fort. Mais si ce dernier était battu, il s'y entendait alors pour écarter son allié par ruse ou violence, et attirer à lui la plupart de ses hommes, qui ne cherchaient qu'un meneur qui leur donnerait le plus d'occasions de pillage. Par de tels procédés, par sa bravoure et par son intelligence, il devint peu à peu le chef de plusieurs milliers d'hommes, et seigneur d'un district important avec quelques petits forts. Mais en ce domaine, il eut, avant et après, beaucoup d'égaux. Grâce aux troubles intérieurs en Perse, de nombreux risque-tout ont pu s'élever de rien jusqu'à devenir des seigneurs indépendants de provinces considérables. Karim Khan lui-même, le souverain actuel de la plus grande partie de l'empire persan, n'est pas d'une origine plus distinguée que Nadir, mais un Kurde d'une petite famille Zand, qui nomadisait sous tentes et se nourrissait principalement de l'élevage de chèvres. Nadir n'a en fait posé les fondations de sa future grandeur que quand il a su au bon moment se rendre nécessaire au Tahmas Chah, auquel les Afghans pour partie, et d'autres rebelles au nombre desquels se comptait Nadir lui-même, avaient enlevé

81. Histoire de Nader Chah, connu sous le nom de Thamas Kuli Khan, empereur de Perse. Traduit d'un manuscrit persan..., par William Jones, Londres 1770.

82. Il faut en fait lire « $393 »$. 
presque toutes ses provinces. Il offrit au roi le district qu'il avait conquis et ses services contre un rebelle plus puissant qui lui avait donné du fil à retordre, il obtint aisément son pardon car il amenait une petite armée.

Tahmas Chah était un maître trop faible pour être même capable de conduire en personne le peu de troupes que les rebelles lui avaient laissé. Il devait se reposer entièrement sur son général, et celui qu'il avait présentement était bien un homme droit, mais il n'était pas un très bon soldat ni très rusé, ou si on veut le dire autrement, il n'était pas aussi malin, il ne connaissait pas les hommes aussi bien que Nadir. Ce dernier aurait pu s'opposer à l'armée du chah et peut-être même la battre. Il restitua néanmoins à leur maître légitime les forts qu'il avait pris et ne demanda à son roi rien de plus que l'honneur de venir à son aide avec ses troupes sous les ordres du général pour chasser les rebelles. Et il fut au début très obéissant aux ordres de ce général. Son voisin et ennemi, trop fort pour lui lorsqu'il était seul, fut bientôt battu. Les Persans aimaient leur roi ; ils ne l'avaient abandonné que parce qu'il n'était pas en état de conduire lui-même une armée, et n'avait en outre aucun officier qui puisse les protéger contre les rebelles. La bravoure de Nadir était connue dans le Khorassan, et la province se soumit en entier en peu de temps. Cela ne suffisait évidemment pas au jeune héros. Au fur et à mesure qu'il amenait les rebelles à l'obéissance ou les chassait complètement, il obtenait un accès plus proche au Chah, et il alla si loin auprès de ce maître faible que ce dernier fit exécuter son vieux et fidèle général. Nadir devint alors le commandant en chef de toutes les troupes de son maître. On fit circuler toutes sortes de nouvelles et de lettres à l'effet de montrer que le général précédent aurait été un traître. En revanche Nadir, qui s'était soumis de son propre gré, qui voulait avoir la réputation de n'avoir depuis le début rien recherché pour lui-même, et qui avait rendu à son maître la possession de tout le Khorassan, était considéré comme un serviteur fidèle. L'armée du roi légitime, qui était dorénavant conduite par un général courageux et vigilant, connut un afflux extraordinaire ; et les provinces l'une après l'autre revinrent bientôt à l'obéissance. À la fin Nadir se mit à craindre qu'un autre puisse s'introduire auprès du souverain par la flatterie, et le faire écarter de sa route comme il l'avait fait avec son prédécesseur. Pour empêcher cela, il s'arrangea pour rendre son roi ridicule auprès des plus grands officiers, pour qu'il soit ensuite déposé dans les formes par une assemblée, qu'un prince, un enfant encore, et de santé fragile, soit élu chah, et lui-même nommé régent de l'empire. Les rebelles appliqueraient la même politique à la mort de Nadir Chah. Certains cherchèrent un descendant de la famille royale (qui ne pouvait descendre que d'une princesse, les princes du sang, comme on le sait, ayant tous été exécutés) au prétexte qu'ils voulaient le placer sur le trône : et ceux-là recevaient en général plus de recrues que les autres rebelles qui ne dissimulaient pas qu'ils voulaient gouverner eux-mêmes. Karim Khan a également réussi son coup par cet artifice. Il s'empara d'un garçon du nom d'Ismaill, dont le père s'était appelé Sayed Mustafa, et dont la mère était une fille du Chah Hussein. Il le 
nomma Ismail Chah, il lui témoigna les honneurs royaux sur le champ de bataille et assura qu'il ne recherchait pas le gouvernement pour lui-même mais pour ce descendant de l'ancienne famille royale. Et maintenant, alors qu'il n'a plus rien à craindre des grands rebelles, il fait rendre dans un fort les honneurs royaux à son Ismail Chah, dont il se nomme le Wekil ou régent, et au reste gouverne seul sans restriction [n. : Dans une annexe à la traduction allemande de l'histoire de Nadir Chah par Mohammed Mahdi Khan, j'ai donné des informations plus détaillées ${ }^{83}$ sur Karim Khan et d'autres rebelles, qui sont devenus célèbres en Perse après la mort de Nadir Chah].

Ayant gouverné en qualité de régent de l'empire jusqu'à la mort du jeune Chah, Nadir organisa la célèbre assemblée des Persans dans la plaine de Mogan ${ }^{84}$. Là, il fit le compte de tous les services qu'il avait rendus à l'empire, et laissa les grands décider s'ils voulaient rappeler Tahmas Chah, qui était encore en vie, ou élire un nouveau roi. Il n'en avait pas moins à côté une armée de 100000 hommes, qui étaient très contents de lui, car sous sa conduite ils avaient presque toujours vaincu, et fait bon butin. C'est alors qu'un de ses partisans, un homme considéré et éloquent, exprima sa pensée selon laquelle personne d'autre ne méritait de gouverner cet empire que le général qui l'avait arraché aux ennemis ; cette proposition fut donc soutenue par l'armée, et aucun des grands, qui voyaient plus loin, n'osa soulever d'objection. Nadir semblait complètement indifférent sur le point de savoir si lui ou un autre était nommé chah ; c'est ainsi qu'il laissa les Persans réfléchir plus avant à cette question importante, et élire comme roi celui qu'ils tiendraient comme le plus utile pour l'empire. Il donna l'assurance qu'il ne souhaitait maintenant, après avoir eu le bonheur de ramener en Perse le calme général, que de pouvoir passer en paix le reste de sa vie dans un district de la province de Khorassan qu'il comptait se réserver.

Nadir avait bien réuni ce que les puissances voisines et les rebelles avaient enlevé à l'empire, et rendu ainsi de grands services au pays. Si on le plaçait sur le trône, on pouvait s'attendre que la Perse conserverait sa grandeur; si au contraire on rappelait le chah légitime ou élisait un des khans qui servaient sous Nadir, il était à craindre que l'armée ne serait pas d'accord et se débanderait aussitôt ; et même que les grands officiers qui, à la mode orientale, conduisaient leurs propres tribus et les troupes qu'ils avaient recrutées, recommenceraient à se partager les provinces. Les Persans se trouvaient donc contraints de mettre Nadir sur le trône : et comme il semblait indifférent à l'élection, on pouvait espérer qu'il en aurait bientôt assez de la guerre, et en qualité de chah rechercherait la paix non seulement pour ses sujets mais aussi pour lui-même. Pendant les jours où il les laissait dans l'incertitude sur le point de savoir s'il accepterait, ou non, de

83. Aucune trace de cette traduction allemande n'a été trouvée ; $c f$. note 81 ci-dessus pour la version française.

84. Au sud-est de l'Iran. 
gouverner, l'armée entière et le reste de l'assemblée étaient magnifiquement régalés.

Non seulement Nadir se reconnaissait dans la secte sunnite, cela était aussi le cas pour une grande partie de l'armée ; car en son sein se trouvaient de nombreux Afghans, Turkmènes, Kurdes et Arabes, qui avaient tous été élevés dans la foi sunnite. On pensait aussi avoir remarqué que le général aimait beaucoup plus ces étrangers que les indigènes, qui étaient chiites. Il était donc très délicat d'élire un roi qui se reconnaissait dans une secte étrangère, et qui avait dans l'armée tant de coreligionnaires, tous conduits par les chefs de leurs tribus. D'un autre côté on n'avait jamais remarqué que tous ces gens se préoccupaient beaucoup de religion; et si Nadir penchait plus vers eux, la raison était à trouver, croyait-on, dans le fait qu'ils étaient depuis leur jeunesse habitués à vivre en grande partie sous la tente, ils étaient plus guerriers de manière générale, et meilleurs soldats que les Persans, qui préféraient se livrer en paix à la culture et à l'artisanat, et voulaient vivre dans le luxe. Jusqu'alors Nadir ne s'était préoccupé de religion que pour chercher à éliminer de son armée la haine religieuse et à maintenir l'unité de ses troupes. On espérait qu'en qualité de chah il resterait aussi tolérant qu'il l'avait été en qualité de général. Là était la très grande erreur des Persans. Il les fit attendre plusieurs jours sans leur faire connaître sa décision sur son acceptation, ou non, de la charge du gouvernement; en fait, s'étant rendu compte qu'ils ne pouvaient élire personne d'autre que lui, il rassembla les grands de l'empire et leur exposa les conséquences désastreuses que les divisions religieuses avaient toujours entraînées. Il leur rappela les guerres sanglantes que cela avait provoquées entre les Turcs et les Persans ; il leur rappela de même que vivaient en Perse de nombreux et dociles Turkmènes, Kurdes et Arabes, en majorité des Sunnites, et bien sûr que l'armée avec laquelle il avait ramené à l'obéissance le grand nombre de rebelles était constituée en partie de Sunnites. Il serait injuste que ces libérateurs du royaume de Perse fussent méprisés comme hérétiques [n. : De même, les Jésuites avaient cru que le roi de $\mathrm{Habach}^{85}$ et tous ses sujets pourraient bien devenir durablement catholiques romains au motif que les Portugais étaient en une occasion venus à son aide contre ses voisins mahométans, Voyage d'Abyssinie du R. P. Jerome Lobo, par le Grand ${ }^{86}$ ] et dussent en permanence entendre les Chiites maudire les trois premiers califes Abou Bakr, Omar et Othman. Les Sunnites, disait-il, n'ont certes pas de dévotion pour eux, mais ils honorent leur mémoire parce qu'ils ont été amis de Mahomet et que la volonté de Dieu a été de les faire choisir comme califes par les Mahométans d'alors qui n'étaient ni Sunnites ni Chiites. Ils ne peuvent plus aujourd'hui, mille ans après leur mort, nuire à quiconque ; Ali, qui a été le quatrième calife, ne peut plus devenir le premier, ni le

85. L'Abyssinie.

86. Il s'agit de la traduction du portugais, Paris 1728. 
deuxième ou troisième, et il est à la fois superstitieux et absurde que les Chiites veuillent maudire les premiers guides des croyants et amis de notre prophète commun. Si vous vous unissez aux Sunnites, continua-t-il, cela ne fera pas que prévenir beaucoup de sang versé, vous ferez ainsi la volonté de Dieu, qui a ordonné aux Mahométans, qui croient en un seul Dieu et en un seul prophète, de s'entr'aimer comme des frères. Les Turcs ont adopté la doctrine d'Abou Hanifa, les Égyptiens celle de Chafii, les Africains celle de Malik, et d'autres ont adopté la doctrine de Ibn Hanbal ; mais tous sont Sunnites, et se regardent entre eux comme orthodoxes et frères. La secte des Chiites est nouvelle, dit-il, c'est elle qui s'est séparée des Sunnites et a, par là, causé beaucoup de malheur. Si vous êtes de véritables Mahométans, alors vous devez chercher à rétablir l'unité entre les adeptes de la doctrine du prophète. Il n'est pas nécessaire que vous vous ralliiez à une des quatre sectes des Sunnites. Vous honorez Jaafar al-Sadiq comme l'un de vos plus grands imams, et vous n'avez pas d'objections à son commentaire du Coran bien qu'il soit plus ancien que la secte chiite. Tenez-vous en simplement à cela, et devenez la cinquième secte des Sunnites sous le nom de Jaafariens. $\mathrm{Si}$ vous ne voulez pas de cela, mais au contraire rester chiites et continuer à haïr les autres Mahométans, je ne demande pas à régner sur la Perse. Après que Nadir eut fait cette proposition sur la modification de la religion, il quitta l'assemblée afin de lui laisser un nouveau délai pour les consultations sur le point de savoir si elle voulait l'élever au trône, lui ou un autre. Pendant ce temps, l'armée avec ses 100000 hommes était sous les armes.

Il ne manqua pas d'hommes éloquents pour souligner non seulement la bravoure du général et les grands services qu'il avait rendus à l'empire mais aussi son zèle pour la religion. On trouva justes ses réflexions contre les autres religions, et son comportement général si désintéressé qu'on croyait devoir tout concéder à un homme si brave et droit qui avait tant à cœur le bien de l'humanité. Cependant certains, qui voyaient plus loin et connaissaient mieux le cœur de Nadir, proposèrent de ne pas être trop pressés en un domaine aussi important que peut l'être le changement de la religion d'un pays et d'interroger d'abord à ce sujet le Cheikh al-Islam (mufti) pour avoir son avis. Celui-ci mit en valeur les mérites du général pour l'empire, et ajouta que personne ne serait mieux placé que Nadir pour maintenir la paix générale, lui qui avait réuni entre elles toutes les provinces. Mais en ce qui concernait le changement de religion, il souhaita que le nouveau chah n'en traitât point au début et transmît cette importante affaire aux clercs pour réflexion approfondie. De hauts cris s'élevèrent aussitôt sur l'orgueil et l'égoïsme des clercs qui dans leur intérêt personnel dressaient un Mahométan contre un autre, qui avaient toujours été la cause des persécutions, etc., et le vieil homme fut massacré par ceux-là mêmes qui peu auparavant avaient parlé si humainement des adeptes de religions apparentées. Il ne se trouva plus personne pour objecter au changement de religion, et Nadir fut déclaré chah. Il fit aussitôt établir un édit, selon lequel il s'était décidé sur l'instance des Persans à accepter la charge du gouvernement 
après qu'ils aient spontanément déclaré qu'ils voulaient se joindre aux Sunnites. Il envoya bientôt des ordres dans toutes les provinces pour que les habitants cessent de maudire les trois premiers califes, mais qu'ils pensent à eux avec honneur en toute occasion et ne célèbrent plus la fête d'Hussein ; en bref, ils devaient cesser d'être des Chiites et constituer sous le nom de Jaafariens la cinquième secte des Sunnites.

Dès l'intronisation de son gouvernement, Nadir Chah montrait par cet ordre ce que les Persans auraient à attendre de lui. Il ne manqua pas de clercs qui trouvèrent excellentes les réflexions du nouveau souverain sur la religion, et ceux-là furent bientôt élevés aux meilleures charges. Et maintenant on parlait beaucoup de l'amour entre les hommes, de la tolérance des adeptes de religions apparentées, de l'éradication de la superstition, etc. On nommait les Chiites des sots hypocrites qui interprétaient injustement le Coran, qui pratiquaient des cérémonies du plus mauvais goût, et croyaient s'acquérir du mérite auprès de Dieu par leurs pleurs et hurlements sur la mort d'Hussein. En dépit des efforts des Jaafariens pour ridiculiser les adeptes de l'ancienne secte, l'expansion de leur nouvelle doctrine n'en allait pas moins toujours très lentement; ils ne pouvaient faire connaître celle-ci par la presse, et il faut bien voir qu'ils n'avaient que peu de charges à distribuer à leurs adeptes, car de manière générale la famille du fondateur d'une mosquée procède elle-même à la nomination des desservants. Ils pouvaient bien les sermonner aussi souvent qu'ils le voulaient sur le mauvais goût et l'inhumanité de leur malédiction des trois califes et de leur persistance à pleurer la mort d'Hussein, les Chiites les avaient invectivés de si nombreuses années qu'ils ne pouvaient en un instant se mettre à les tenir pour des gens droits : et comme ils avaient si souvent trouvé consolation en pleurant la mort du petit-fils de leur prophète, ils ne voulaient pas non plus qu'on les en privât. Par ailleurs, en observant ce que faisaient les Jaafariens, on s'apercevait qu'ils n'avaient pas amélioré leur cœur par la religion. Lorsque les clercs chiites étaient accusés d'être ambitieux, on remarquait que les Jaafariens recherchaient volontiers les prébendes et la considération. Si l'on accusait ceux-là de superstition, c'est d'incroyance que l'on accusait ceux-ci, car on pensait avoir observé que leurs clercs ne se rendaient à la mosquée que parce qu'ils étaient payés devant elle, et que les laïques se préoccupaient peu de la religion car ils s'imaginaient avoir déjà fait de grands progrès en n'étant plus superstitieux. Lorsqu'on reprochait aux Chiites d'être les ennemis jurés des autres Mahométans, on blâmait tout aussi fort les Jaafariens, qui prétendaient être si amicaux envers les autres Mahométans, d'être maintenant les ennemis les plus perfides des adeptes de la secte de leurs propres ancêtres. Cette dernière constatation ne concordait pas du tout avec leurs doctrines. On nomma Nadir Chah un hérétique, un incroyant qui s'était débarrassé de la famille de leur légitime, et selon eux, orthodoxe souverain, et qui s'était emparé du trône par la ruse et la violence. Les sujets s'insurgeaient lorsque la moindre occasion s'en présentait. Tout au contraire Nadir, qui se considérait comme un libérateur des Persans du 
joug des tyrans indigènes (au nombre desquels il oubliait de se compter), des Afghans, Turcs et Russes, qui voulait même se donner la réputation de ne s'être laissé convaincre d'accepter la couronne que sur leur prière, Nadir tenait les Persans pour des ingrats. Il punit les rebelles : et comme en dépit de cela il se trouvait toujours d'autres meneurs, contre lesquels il l'emporta continuellement, il devint peu à peu un tyran très cruel. Si Nadir Chah n'avait procédé à aucun changement de religion, ses sujets auraient eu plus d'amour pour lui, et il aurait en plus probablement pu déposer le sultan de Turquie et piller Constantinople, tout comme il avait déposé le Mogol et pillé Delhi. C'est ainsi que sa vie fut une guerre constante. Il n'avait pas à combattre que les ennemis de l'extérieur, continuellement aussi des rebelles, et en fin de compte, après qu'il ait complètement appauvri et dépeuplé le pays tout en étant toujours vainqueur, il fut une nuit assassiné dans sa tente.

Nadir Chah ne se préoccupait en vérité pas de la religion, il ne faisait que s'abandonner à ses passions principales, orgueil, despotisme et avarice. On disait qu'il avait été jusqu'à vouloir faire des religions mahométane, chrétienne et juive une religion universelle ; précisément dans cette intention, il avait fait traduire en langue persane le Nouveau Testament par un moine catholique et les livres de Moïse par des Juifs, et chargé des savants mahométans de tirer de cela et du Coran un nouveau code. Était-ce fondé, je ne puis l'affirmer. Qu'il ait travaillé avec sérieux à réunir les sectes sunnite et chiite nous a été rapporté de façon circonstanciée par Mohammad Mahdi Khan. Dans la quasi-certitude où il était que le sultan n'aurait aucune objection à la constitution d'une $5^{\mathrm{e}}$ secte sunnite parce que Jaafar, tout comme Abou Hanifa et les autres maîtres orthodoxes, avait vécu avant la naissance de la secte chiite, il envoya un légat à Constantinople [n. : Histoire de Nadir Chah par Mohamed Mahdi Khan, p. 237 de la traduction allemande] aussitôt après son accession au trône avec les instructions suivantes :

1) Considérant que nous avons rejeté nos opinions antérieures et adopté la doctrine sunnite, mais considérant encore que nous reconnaissons la haute dignité de Jaafar le Véritable - que la paix du Seigneur repose sur lui-, que les savants et instructeurs turcs confirment notre adhésion et nous considèrent comme la cinquième secte,

2) Considérant qu'en raison de l'existence dans le temple sacré de La Mecque de quatre maisons de prières en l'honneur des quatre sectes [n. : Beschr. Arab., p. 362], il est souhaitable d'en faire édifier encore une en l'honneur de Jaafar,

3) Considérant que, chaque année, lorsque pour la protection des pèlerins persans un amir al-Hadj ou guide des pèlerins est envoyé de Perse en compagnie des émirs égyptien et syrien, il est souhaitable qu'un autre émir, en dehors de La Porte ${ }^{87}$, s'unisse à eux dans la même intention. [n. : Peut-

87. Il faut sans doute comprendre «nommé par le gouvernement persan», et non plus par « la Porte», le sultan. 
être trouverait-on dans l'original persan que, comme des guides turcs accompagnent tous les ans les pèlerins de Syrie et d'Égypte, un guide persan devrait également recevoir l'autorisation de voyager avec les pèlerins persans $]^{88}$,

4) Considérant que tous les prisonniers des deux empires devraient être libérés et un commerce libre régner entre les deux nations,

5) Chacun des souverains des deux empires entretiendra des délégués à la cour de l'autre, ils seront chargés de régler les affaires et de consolider la paix entre eux.

Si le sultan concéda immédiatement les deux derniers points, il s'excusa de ne pouvoir accepter la proposition concernant la nouvelle secte ni lui accorder une maison de prières à La Mecque. Il proposa, en ce qui concernait les pèlerins persans, que ceux-ci ne prennent pas l'itinéraire par la Syrie mais voyagent à travers le désert tout droit vers La Mecque en passant par Meched Ali, car entre-temps le pacha de Bagdad pourvoirait à la sécurité du chemin, c'est-à-dire leur fournirait un chef de caravane. Je me souviens avoir entendu dire à Bagdad à propos de cet article que les Turcs auraient craint qu'il puisse venir à l'esprit de Nadir Chah ou d'un souverain persan postérieur de faire un pèlerinage avec son armée et de profiter de l'occasion pour dépouiller non seulement tous les pèlerins sunnites mais aussi la Kaaba et la tombe de Mahomet, et conquérir la Syrie. Cette crainte n'était pas infondée. Divers légats furent encore envoyés de Perse à Constantinople et d'ici en Perse pour les deux points mentionnés ; Nadir écrivit même au sultan : "Il serait déterminé à se rendre lui-même en Turquie dans un esprit d'amitié et de fraternité, car il espérait que cette grande affaire pourrait être conclue à la satisfaction des deux parties au cours d'un entretien entre lui et le sultan" ; les choses en restèrent cependant toujours là. La seule chose est qu'un chef de caravane turc fut envoyé de Bagdad droit vers La Mecque, et c'est avec lui que voyagèrent les pèlerins persans ${ }^{89}$.

Les Turcs n'ayant absolument pas voulu recevoir parmi les Sunnites orthodoxes la secte des Jaafariens proposée par Nadir Chah, il finit par faire lui-même (en 1743) un pèlerinage à Meched Ali. Il avait rassemblé là non seulement des savants en provenance de Perse, qui étaient à l'origine des Chiites, mais aussi en provenance d'Afghanistan, de la Bactriane ${ }^{90}$ ou de la région de Boukhara ${ }^{91}$, où les habitants sont des Sunnites. Ils furent contraints d'endurer un rapport sans fin sur la raison pour laquelle il voulait supprimer

88. Cette note de bas de page semble trahir de la part de $\mathrm{CN}$ une certaine incompréhension du sens précis de la troisième demande : Nadir Chah réclame du sultan, destinataire du message, le droit de nommer lui-même, et seul, un responsable persan pour accompagner les pèlerins persans.

89. Pour le retour seulement ? le passage semble corrompu.

90. Province du nord de l'Afghanistan.

91. En Ouzbékistan. 
la secte chiite et sur tous les pourparlers avec le sultan turc, en y ajoutant la nouvelle profession de foi [n. : Histoire de Nadir Chah, p. 372 de la traduction allemande]. Tout ceci fut signé par les savants des deux parties qui étaient présents. Une copie fut déposée auprès de la mosquée d'ici et d'autres furent rendues publiques dans toute la Perse. Toutefois, nonobstant tous ces efforts de Nadir Chah, les Persans aussi bien que les habitants de Meched Ali et Meched Hussein sont toujours demeurés chiites et peut-être de nos jours plus mauvais Mahométans qu'auparavant. ${ }^{92}{ }$ '

\section{j) t. II, 433-43893 «Religion des Druses »}

«Comme les Druses ne veulent pas que leur religion soit connue des Turcs, ils n'en ont d'ailleurs pas le droit, car on entamerait alors contre eux une guerre de religion, ils se nomment donc Mahométans. L'émir régnant et d'autres notables, qui de temps à autre ont des affaires avec le pacha et d'autres Turcs importants, sont circoncis. ; ils apprennent bien sûr la prière et les rites qui l'accompagnent afin de pouvoir se présenter comme des Mahométans. Mais au reste, ils ne se préoccupent en rien de la religion mahométane. Ils ont bien une mosquée à Deir el-Kammar, mais, pour ainsi dire, seulement dans le but de traiter leurs hôtes de qualité. Lorsque l'émir attend la visite d'un aga, la mosquée est nettoyée ; et aussi longtemps que son hôte est chez lui, l'office mahométan y est tenu. Autrement, elle est vide, et le minaret n'est alors pas utilisé pour appeler la communauté à la prière, mais seulement pour faire savoir que quelqu'un a perdu un mouton ou un mulet, ou à quel prix la viande et d'autres aliments doivent être vendus sur le marché. Avec les Chrétiens, les Druses ne font pas que boire du vin et d'autres boissons fortes, ils mangent tout, même de la viande de porc. Lorsqu'ils séjournent dans un village où vivent en nombre des Maronites, alors ils se rendent souvent à l'église, en particulier les dames druses distinguées. Et s'il arrive qu'un moine européen ou un évêque maronite veuille baptiser le fils ou la fille d'un émir, on lui accorde cet honneur ; on a même des exemples de vieux émirs et cheikhs croyant que leurs descendants tireraient avantage de l'amitié des Chrétiens qui se faisaient baptiser sur leur lit de mort. Mais dans la vie ils sont restés de vrais djahel, c'est-à-dire des gens qui ne se préoccupent d'aucune religion ${ }^{94}$. De temps à autre, très rarement toutefois, un émir ou cheikh âgé ou qui a subi

92. L'épisode Nadir dans l'histoire de la région est remarquablement décrit dans ses aspects géopolitiques et religieux par André Miquel dans L'Islam et sa civilisation, Paris 1968.

93. Texte extrait d'une section de Reisebeschr. intitulée « Observations sur la Syrie et particulièrement sur les habitants du Mont Liban » (423-479) qui contient de grands développements sur les Druses.

94. Sens général : « ignorant». 
de nombreux déboires choisit l'état d'aqil ${ }^{95}$, pour passer en paix le restant de ses jours. On a de fréquents exemples de Druses fixés à Damas, Alep ou Saïda ${ }^{96}$, qui se font Mahométans ; les Druses n'acceptent cependant pas de prosélytes, comme cela sera indiqué ci-dessous.

La loi, ou peut-être seulement l'habitude, permet aux Druses la polygamie. On n'en trouve pourtant pas beaucoup qui ont plus d'une femme; et même chez les notables il est extrêmement rare d'en avoir plus de deux. Chez eux, avant le mariage, en présence d'un aqil comme chez les Mahométans en présence d'un cadi, un accord est passé avec la parenté de la fiancée pour définir ce que le mari devra donner à son épouse s'il la répudie. Lorsque le Mahométan veut se séparer de sa femme, il doit recourir au cadi, une cérémonie semblable est probablement exigée chez les Druses. On m'a fait comprendre que ces derniers pour cela n'avaient pas toujours besoin de beaucoup de formalités. Si, par exemple, une femme demande l'autorisation de se rendre chez ses parents et le mari lui dit simplement : "va", et non : "va et reviens", il l'aurait par là déjà répudié.

Les Druses distingués apparaissent tous à cheval pour l'enterrement de leurs parents décédés et leur rendent, à leur manière, beaucoup d'honneurs militaires [n. : c'est exactement ce qu'on m'a raconté des Bédouins]. On disait aussi qu'ils habillent de vêtements du défunt une gerbe de blé ou un morceau de bois, qu'ils portent cela pendant 7 jours au village et dans les champs environnants et le déshabillent sur la tombe du défunt à l'issue de ce délai. En général, à l'occasion du mariage et de l'enterrement des Druses distingués, un très grand nombre de gens se rassemblent : et comme ils doivent tous être régalés, de telles festivités sont donc chez eux très coûteuses.

C'est de Maronites ayant vécu de nombreuses années sur le Mont Liban que j'ai obtenu les informations qui précédaient sur les mœurs et usages des Druses. Ils avaient bien eu dès leur jeunesse des rapports avec les Druses laïques, mais non avec leurs clercs. Ils n'avaient donc pas été en mesure de me donner des nouvelles de leur religion et de leurs cérémonies. On ne peut d'ailleurs juger de la religion de nations étrangères d'après quelques cérémonies et usages, et encore moins d'après les informations de leurs voisins, ces derniers étant généralement leurs plus grands ennemis et présentant tout en mauvaise part. J'ai donc cherché un livre dans lequel un Druse donnerait lui-même des renseignements sur sa religion, et j'ai finalement pu l'obtenir de Antoun Beitar, le premier interprète de M. van Masseyk. Un Jésuite connaissant parfaitement la langue arabe auquel un Druse hospitalier avait offert un hébergement pour la nuit l'aurait trouvé dans un coin de sa chambre et aussitôt copié, dans la même nuit. C'est dans ce petit livre que j'ai relevé ce qui suit.

95. « sage, initié », au pluriel uqala, voir ci-dessous.

96. L'ancienne Sidon, aujourd'hui au Liban. 
*Al-Dursi ${ }^{97}$, ou bien, comme les Européens les appellent ordinairement, les Druses, suivent la doctrine de Mohammad ibn Ismail, et prient al-Hakim comme Dieu [n. : Cet Hakim était calife d'Égypte ${ }^{98}$. Dans l'Histoire des souverains d'Égypte par Marais, Büschings Magazin, $5^{\mathrm{e}}$ partie, $384^{99}$, et dans la Allgemeine Welthistorie, t. XX, 493, il est décrit comme un souverain athée. Dans les deux passages, la nouvelle secte de Mohammad ibn Ismaïl est également mentionnée]. Ils se nomment aussi mouwahhidin ${ }^{100}$. Ils croient que, dans la 400 année de l'hégire (1009 après la naissance du Christ), la Divinité est allée à Hakim, mais ne s'était pas révélée aux hommes avant 408, lorsque Mohammad ibn Ismaïl commença à répandre sa nouvelle religion. Les Druses nomment la 409ª année l'année de la désolation car la Divinité aurait quitté leur Hakim cette année-là. Dieu l'aurait pourtant habité à nouveau de la 410 e année au début de la $412^{\mathrm{e}}$ (lorsqu'il mourut) ${ }^{101}$.

Selon le petit livre évoqué, Dieu serait apparu dix fois sous forme humaine, à savoir : 1) sous le nom al-Ali en Inde, dans la ville de Tchin ma tchin. 2) sous le nom al-Baar à Ispahan. 3) sous le nom Alia au Yémen. 4) sous le nom al-Maala en Barbarie. 5) sous le nom al-Qaïm à Mohhdi en Barbarie. 6) sous le nom al-Maas. 7) sous le nom al-Asis. 8) sous le nom Abou Zacharia. 9) sous le nom al-Mansour. 10) sous le nom Hakim comme roi d'Égypte.

Les messagers les plus distingués de Mohammad ibn Ismaïl ont été : 1) Hamza. 2) Ismaiil. 3) Mohammad al-Kilme. 4) Abou al-Chair. 5) Baha al-Din ou Ali ibn Mohammad Essemouki.

Bien que fondateur de la religion des Druses, Mohammad ibn Ismail n'est mentionné que très rarement dans le petit livre. En revanche l'auteur parle souvent de Hamza ibn Ali, sans doute le premier des messagers évoqués, qui serait apparu sept fois dans le monde, à savoir : 1) au temps d'Adam sous le nom de Chat. 2) au temps de Noé sous le nom de Pythagoras. 3) au temps d'Abraham sous le nom de David. 4) au temps de Moïse sous le nom de Chuaïb (Jethro). 5) au temps du Christ sous le nom d'Eléazar. 6) au temps de Mahomet sous le nom de Salman le Persan. 7) au temps de

97. Ce terme désigne en fait un membre mâle de la communauté druse.

98. De 996 à 1021.

99. Cette traduction allemande est l'œuvre de l'orientaliste Johann Jakob Reiske (1716-1774), avec lequel $\mathrm{CN}$ a travaillé à son retour et pour lequel il exprime une grande estime, cf. Beschr. Arab., XXV-XXVI.

100. «Monothéistes ».

101. Pour appréhender ce calcul, il faut se souvenir que le calendrier musulman (calendrier hijri) se fonde sur l'année lunaire, plus courte de 11 jours que notre année civile ; l'hégire étant normalement datée du vendredi 16 juillet 622 de l'ère chrétienne, la $400^{e}$ année de l'hégire devrait être $622+(400 * 354)$ $=141600$ jours $/ 388$ ans, donc $622+388=1010$, donc très proche du 1009 indiqué (pour les détails, cf. Beschr. Arab., 108-112 et F. Wüstenfeld, VergleichungsTabellen der Muhammedanischen \& Christlichen Zeitrechnung, Leipzig 1854). 
Saïd sous le nom de Saleh. Le plus important recueil de lois des Druses a été écrit par lui. Sont ensuite tenues en grande estime les œuvres d'Ismaïl et de Baha al-Din. Le Nouveau Testament est le livre des autres religions qu'ils apprécient le plus. Sauf que, selon eux, il a également été écrit par Hamza. Ce dernier, sous la forme d'un messager, a été le vrai Messie, et a enseigné les lois à Jésus, le fils de Marie, que l'auteur appelle le faux Messie. Les âmes des autres messagers des Druses doivent aussi avoir habité les apôtres et messagers du Christ.

Les Druses se servent également des mots ange et diable, qui désignent pour eux le premier, ceux qui croient en Hakim, le second, les incroyants. Ils disent que les cinq anges qui portent le trône de Dieu sont 5 messagers (vizirs) de leur maître, à savoir : 1) Gabriel recouvre Hamza, 2) Michel, Mohammad ibn Wahab. 3) Israfil, Salame ibn Abd al-Wahab. 4) Asraeil, Baha al-Din. 5) Matarin, Ali ibn Ahmed. Chacun d'eux a aussi un surnom : l'Ancien, le Constant, la Trompette, etc.

Ils croient encore que Hakim reviendra sur terre sous forme humaine, et on pourra s'y attendre lorsque les Chrétiens auront remporté de grandes victoires sur les Mahométans. Hakim s'assujettira alors le monde par l'épée et placera les Druses au-dessus des adeptes de toutes les autres religions. Parmi ceux-ci, les Chrétiens s'en sortiront le mieux, mais les Mahométans le plus mal.

Afin de pouvoir démasquer un étranger qui se ferait passer pour un Druse profane (ce qui pourrait aisément se produire car ces derniers savent peu sur la religion, ou rien du tout), ils lui demandent : "dans votre pays, les paysans sèment-ils aussi des hab el haled ?" (je pense que ce mot signifie "lentilles"). S'il répond: "oui, elles sont semées dans les cœurs des croyants", ils voient là un signe qu'il appartient à leur communauté [n. : les Chrétiens orientaux d'Alep, qui ont entendu dire que les Anglais du lieu tiennent parfois des réunions portes fermées et disposent de certains signes par lesquels ils sont en mesure de reconnaître chacun des membres de leur groupe, ont voulu déduire de cela que les Druses sont francs-maçons. Je veux observer en passant que l'on n'a pas en Alep de si mauvaises opinions sur les francs-maçons que dans plus d'une ville en Europe. Les frères ont pendant longtemps fait parvenir dans les prisons du pain - qu'ils faisaient distribuer sans distinction aux Mahométans, Chrétiens et Juifs - sans que l'on puisse apprendre d'où provenait ce bienfait pour les malheureux. On finit par le savoir. On parla beaucoup de ces Européens, qui, comme les Druses et les Ismaélites, se réunissaient portes fermées. On ne crut cependant pas que des gens qui menaient une vie irréprochable et faisaient si généreusement l'aumône puissent dans leurs réunions commettre des actes condamnables]. Ils n'acceptent pas de prosélytes. Ils disent qu'un étranger, même s'il voulait se convertir en toute orthodoxie, retournerait à sa mort en sa religion première avec ses frères. Le livre serait refermé, et la plume sèche. 
De passages répartis dans le petit livre j'ai retiré sur les devoirs des Druses ce qui suit. Il doit honorer Hakim comme Dieu, et croire ce que les aqqal $^{102}$ lui disent de la religion sans chercher à faire de recherches à ce propos. Il doit croire que l'âme d'un défunt ira aussitôt revivre dans un homme nouveau-né. Il ne doit pas jurer, mais répondre à tout par oui ou non. Il ne doit pas dissimuler à son épouse les secrets de sa religion, mais de la sagesse de cette dernière il ne doit rien révéler à un étranger. Il doit vivre retiré et faire l'aumône à ses frères clercs. Un Druse doit de plus croire que les adeptes d'autres religions, en particulier leurs grands personnages qui s'emparent du patrimoine de leurs sujets, seront tout le temps méprisés par Hakim (Dieu). Il n'a pas le droit de manger près d'eux, mais tout au contraire doit-il beaucoup estimer comme légitimement acquis le patrimoine des clercs (uqala), et celui des orphelins et de ceux qui vivent des travaux des champs. L'adultère est interdit. Notre auteur dit : si un clerc (aqil) a commis l'adultère et le regrette, il doit aller ça et là pendant sept ans chez ses frères clercs et pleurer sur son crime. $\mathrm{Si}$ au contraire il ne le regrette pas, ne fait pas pénitence, alors son âme ira après sa mort revivre dans un incroyant. »

\section{k) t. II, 439-444 « La religion des Noussairiens ${ }^{103} »$}

« Les *Noussairiens ont de même une religion qu'ils cachent aux étrangers. Toutefois leurs chefs, qui ont souvent des affaires avec les Turcs, se nomment aussi sunnites [n. : Schultz a rencontré à Antioche et sur la route d'Alep des gens qui, vêtus comme des Mahométans, se disaient envers lui Chrétiens (nasrani), et il les tenait pour des Samaritains. Ils étaient probablement Noussairiens, ou adeptes d'une des autres sectes ci-dessus]. Leur plus important centre se trouve entre le Mont Liban et Antioche. Un de leurs muqaddem [n.: Le titre muqaddam* est plus que cheikh et moins qu'émir. Je n'ai rien entendu sur ce point ailleurs que chez les Noussairiens et Druses. "Djindi est également un titre de noblesse des Noussairiens] habite à Bahluli, non loin de Lattaquié ${ }^{104}$, et c'est d'ailleurs le plus puissant chez les Noussairiens. Des muqaddem habitent de même à Sumrin, à Belad alChoabe et dans le district de Safita ${ }^{105}$, un autre de leurs cheikhs a pris à ferme une partie du Djebel Kalbie*. Tous paient un tribut au pacha de Tripoli ${ }^{106}$.

102. «Initiés », ou « sages », mais quelques lignes plus loin, CN parle de « clercs ».

103. On disait aussi «nosaïris ». Connus aujourd'hui en Syrie sous le nom d'Alaouites, il ne faut pas les confondre avec les Nizarites, ou Ismaélites Khodjas, qui reconnaissent l'Agha Khan comme chef.

104. Grand port syrien.

105. Localités dans l'arrière-pays de Tartous, l'autre grand port syrien.

106. Grand port aujourd'hui au Liban. 
Leurs districts sont relativement lucratifs car ils produisent la majeure partie de l'excellent tabac exporté de Lattaquié. Cette nation est pourtant de loin moins nombreuse que celle des Druses ; elle n'est pas établie dans de si hautes montagnes, et doit de ce fait se montrer plus soumise aux Turcs. Un Maronite qui les avait beaucoup fréquentés parlait d'eux comme de gens bons et honnêtes. Ils l'avaient conduit dans un de leurs temples, il l'avait trouvé propre et recouvert de marbre, sinon rien de remarquable autre qu'une lampe allumée. C'est également de lui que j'ai appris que les Noussairiens avaient trois grands jours de fête, lors desquels, après l'office divin, ils dansaient. Je n'ai rien pu apprendre sur la religion des Noussairiens de la part des Chrétiens orientaux ni des Mahométans. Ces derniers les nomment païens, qui prient le soleil et la lune. C'est peut-être leur grande vénération de Zahra qui a conduit à cette déduction ; le mot Zahra désigne en arabe non seulement la planète Vénus mais aussi Fatima, la fille de Mahomet. La suite va montrer clairement qu'il s'agit bien des Noussairiens, dont fit état Sale dans son Preliminary Discourse, p. 176 [n. : A leur sujet, on peut également se référer à Pocockii specimen historiae Arabum, p. 25 \& 265, et à History of the Ottoman Empire par Ricaut, p. 227], et qu'ils peuvent donc être comptés au nombre des Mahométans.

L'auteur du petit livre sur la religion des Druses précédemment évoqué dit : les Noussairiens ont autrefois été des Druses, mais l'un d'entre eux les avait entraînés à nier la divinité de Hakim et à vénérer comme Dieu en ses lieu et place Ali ibn Abi Talib (le gendre de Mahomet). Le même leur avait encore enseigné que la divinité avait habité les 12 imams de la maison d'Ali, mais avait disparu avec Mohammad al-Mahdi (le dernier de ces imams, p. 272 ci-dessus) et habitait maintenant le soleil. Le Druse dit aussi que les Noussairiens croient à la métempsycose : l'âme d'un homme pieux parmi leurs coreligionnaires passerait à sa mort dans un autre Noussairien puis, après un certain délai, dans une étoile. Si l'un d'entre eux est désobéissant et ne suit pas le commandement d'Ali, son âme se retrouvera chez un Juif, un Sunnite ou un Chrétien et se transformera fréquemment jusqu'à purification pour pouvoir enfin s'élever en une étoile. Les âmes des incroyants qui n'adorent pas Ali ibn Abi Talib iront dans des chameaux, mules, ânes, chiens, moutons et autres animaux.

Ces informations concordent à peu près avec celles que j'ai trouvées dans un petit livre sur la religion des Noussairiens que m'a également procuré Antoun Beitar. Des agents de la justice turque qui avaient une nuit arrêté un Noussairien et l'avaient traîné en prison auraient découvert ce livre dans sa maison. Il s'agissait de l'original de l'ouvrage, incomplet, mal écrit et rempli de si nombreuses formulations équivoques que l'auteur luimême écrit quelque part : les Noussairiens ont construit un mur devant le pays de Gog et Magog, ou ils se sont servis dans leurs livres de formulations équivoques pour dissimuler leurs secrets aux incroyants. Un non-Noussairien ne comprendra pas l'auteur lorsqu'il appelle messagers cachés p. e. Gabriel, la corneille, l'arche, l'anneau, Belqis, le bâton de Moïse, le dromadaire de 
Salih, la vache des Israélites, etc. On trouve de telles expressions à chaque page, et leur signification n'est pas expliquée. Voici les observations que j'en ai tirées.

Les Noussairiens se nomment muminun ${ }^{107}$. Ils parlent de l'unité de Dieu, donc d'Ali, qui est sorti de l'œil du soleil et jugera le monde, et de 5 personnes en une. Elles s'appellent : 1) Maana (la raison). 2) Ism (le nom). En lui est toujours la vraie sagesse, et il est toujours accompagné de Maana. 3) Bab (le portail). 4) Aytam (les orphelins). 5) Hussein. Moi qui n'ai pas été initié aux mystères de cette religion, je n'entends rien du tout à cette unité en cinq personnes. Je ne saisis pas plus ce qui va suivre, mais j'ai voulu le rapporter car cela constitue les éléments principaux de la doctrine des Noussairiens. Que celui qui n'a pas envie de tout lire saute le passage.

Dieu est apparu sept fois dans le monde.

- La première fois : 1) Maana, Abel. 2) Ism, Adam. 3) Bab, Gabriel. 4) Aytam, il s'agit à nouveau de 5 personnes (a) Michel (peut-être l'archange). b) Israfil (peut-être l'ange dont les Mahométans disent qu'il sonnera au Jugement Dernier). c) Asrael (peut-être l'ange de la mort). d) Malek (peutêtre le portier de l'enfer chez les Mahométans). e) Ridouan (peut-être le portier du ciel). 5) Hussein qui est apparu la première fois sous le nom de Kasch ibn Meflouk. Les ennemis de la divinité la première fois où elle s'est faite homme étaient : 1) Kabil (Caïn). 2) Anak (sœur de Caïn). 3) Bahlou (vizir de Caïn). 4) le serpent. 5) le paon.

- La deuxième fois : 1) Maana, Chid (Seth). 2) Ism, Noé. 3) Bab, Iael ibn Fatim. 4) Aytam (soit a) Ankil. b) Effrakoun. c) Kinan. d) Effrikakil. e) Effrikaou. 5) Hussein est apparu en la personne de Haouch. Les ennemis de la divinité étaient cette fois : 1) Ham ibn Noé. 2) Cheikh Hassa. 3) Jaouk. 4) Jafout. 5) Nisser.

- La troisième fois : 1) Maana, Joseph. 2) Ism, Jacob. 3) Bab, Ham ibn Kouch. 4) Aytam (soit a) Jahoud. b) Hachour. c) Malek. d) Mamlek. e) Ankil). 5) Hussein est apparu en la personne de Mambe ibn Mansour. Les ennemis qui s'opposèrent cette fois à la divinité étaient : 1) Chadjeldoul. 2) Sima. 3) le roi de l'Inde. 4) Habtar. 5) Naatel.

- La quatrième fois : 1) Maana, Josué. 2) Ism, Moïse. 3) Bab, Dan ibn Sabacht. 4) Aytam (soit a) Jahoudan. b) Harouk. c) Abdulla. d) Israël. e) Omran. 5)Hussein était Roubil ibn Saleh. Le parti adverse était constitué de : 1) Pharaon. 2) Haman. 3) Karoun.

- La cinquième fois : 1) Maana, Assaff [Assaff était le vizir du roi Salomon. C'est d'après lui que les Turcs nomment encore Assaff un vizir courageux et sage]. 2) Ism, Salomon. 3) Bab, Abdulla ibn Chamaan. 4) Aytam (a) Chaeira. b) Chadlah. c) Harnache. d) Maskoul. e) Assir). 5) Hussein est apparu sous le nom de Jantores Dekne. Les ennemis de la divinité étaient cette fois : 1) Nemrod. 2) Aad. 3) Samoud.

107. « Croyants ». 
- La sixième fois : 1) Maana, Schemmaoun (Pierre). 2) Ism, Jésus. 3) Bab, Rizoba ibn Merzaban. 4) Itam (a) Jean foum essahab. b) Jean Delami. c) Paul. d) Pierre. e) Mathieu). 5) Hussein était Aijouch ibn Mankidja. Le parti adverse consistait en : 1) Hérode. 2) Jabs. 3) Taous.

- La septième fois : 1) Maana, Ali. 2) Ism, Mahomet al-Hamd (le louangé). 3) Bab, Soulayman ibn Bouheire al-Khidr. 4) Aytam (soit a) Makdad ibn al-Assouad al-Kindi. b) Aboudour Jendab ibn Jounada alGafari. c) Abdullah ibn Rouha al-Nassari. d) Othman ibn Madoun Nadjechi. e) Kambar ibn Kaden Doussi). 5) Hussein s'appelait cette fois Hamdan. Le parti opposé à la divinité était : 1) Abou Sammel. 2) Segdou. 3) Sedjkouk.

L'auteur écrit à un autre endroit : un Noussairien doit croire que Mahomet, Fatir (Fatima), Hassan, Hussein et Mouhssin sont un et signifient Ali. De plus, un mumin doit croire qu'il y a toujours eu 5 Aytam (orphelins), 12 Naqib (chefs de la famille de Mahomet), 28 Noujaba (choisis), Moukhtassin (particuliers), Moukhlissin (dévots), Mountakhabin (prédestinés). Il doit de même tenir les 4 Sittar pour vrais, à savoir : 1) Sitr al-Imam, soit la suite des imams d'Abel à Ali. 2) Sitter al-Imma, c'est-à-dire les patriarches du premier Hassan au dernier Hassan. 3) Sitter Rissala ou la suite des messagers tels Idriss, Noé, Houd, etc. 4) Sitr Nouboua, la suite des poètes ou hommes honorables Anouch, Ichaq, Jacob, etc.

Notre auteur appelle prophètes Adam, Abraham, Moïse, Jésus et Mahomet ; et messagers Jael, Hamroudan, Abdullah, Salman, Aboulkhatil, Mohammad, Moufdil et Abou khaïb. Il désigne un Ichaq comme le plus grand ennemi des Noussairiens parce qu'il a voulu tuer Sayïd Abou khaïb [n. : Parmi les sectes des chiites, Sale en évoque une nommée d'après un Ichaq. S'agirait-il de l'Ichaq mentionné ci-dessus ? Les Metaouali seraientils ichaqiens? Je laisse ces questions à l'examen des voyageurs futurs].

L'âme d'un Noussairien très pieux peut déjà parvenir au Paradis même si elle n'a vécu qu'en quelques hembden (corps). Alors qu'il faudra 80 hembden à l'âme d'un autre. Ils nomment ce dernier cas l'Enfer. Les âmes des incroyants doivent passer par 5 degrés abominables (Fesgh, Nesgh, Mesgh, Wesgh et Resgh) pour ensuite rester dans le monde comme moutons jusqu'au retour de Zahra (Fatima) (Qui pourrait croire que les fondateurs de telles religions trouvent des adeptes !).

J'ai également trouvé dans le petit livre des Noussairiens que Maana leur aurait interdit de manger du chameau, du lièvre et de l'anguille. Ism ne leur aurait autorisé ni la viande de cochon, ni le sang, en définitive aucune viande d'animal qui n'aurait pas été abattu selon la règle; et Bab leur interdirait de consommer le zellor (un certain poisson noir de l'Oronte) et tout ce qui aurait été brûlé. L'auteur exige au surplus des Noussairiens : qu'ils ne découvrent rien de leur religion aux étrangers; qu'ils aiment leurs frères ; qu'ils soient généreux ; qu'ils ne volent pas ; qu'ils n'invectivent ni ne jurent; qu'ils supportent patiemment la pauvreté, et qu'ils acceptent de se faire mal recevoir également par leurs femmes. » 


\section{l) t. II, 444 « Religion des Ismaélites ${ }^{108}$ »}

« Je n'ai rien appris avec certitude sur la religion des Ismaélites, ni vu un de leurs livres. Les Mahométans et les Chrétiens orientaux racontent des choses incroyables à leur sujet. Par exemple que leurs compagnes mariées se rassemblent une nuit en une pièce obscure, qu'à un moment donné le même nombre d'hommes les suit, et que chacun prend son plaisir avec la personne rencontrée dans l'obscurité pendant que dans une pièce voisine un clerc lit quelques passages d'un livre. Ils considéreraient également comme permis qu'un père ait commerce avec sa fille de même qu'un jardinier peut manger les fruits de l'arbre qu'il a planté. Quelques-uns disent que, lors de réunions de ces Ismaélites, une jeune femme s'assied dévoilée sur un point haut, comme sur un autel, et qu'une certaine partie de son corps est adorée par la communauté. C'est pourquoi on l'appelle Abou al-Farj. Mais n'a-t-on pas depuis toujours raconté des choses dégoûtantes sur les éléments et usages religieux de nations que l'on ne connaissait ni pour les avoir fréquentées de près ni encore moins par leurs livres ? Le nombre de ces Ismaélites n'est pas élevé. Leur centre le plus important est à Killis, une bourgade entre Chugr et Hama, et sur le Djebel Kalbie, une montagne peu éloignée de Lattaquié. On les nomme Keftiin entre Alep et Antioche ${ }^{109}$, du nom d'un village de cette région, alors qu'on les traite d'éteigneurs de lumières autour de Mossoul, et chez les Kurdes et Turkmènes entre ici et Constantinople, oui, dans la capitale même du sultan, de begk dachli (seigneurs du rocher), ce sont eux qui auraient les pratiques religieuses honteuses évoquées. La vérité est que je n'ai jamais rencontré quiconque aurait été présent à leurs réunions, ou qui aurait lu un seul de leurs livres. Il faut au surplus espérer que leur moralité n'est pas aussi dépravée qu'on le proclame. »

108. CN ne semble pas avoir compris que plusieurs des communautés qu'il évoque appartiennent aux différents courants de l'ismaélisme. Les allégations de débauche évoquées ci-dessous perdurent.

109. Aujourd'hui la ville d'Antakya en Turquie. 


\section{Postface}

Lorsqu' on termine la lecture des différents textes que $\mathrm{CN}$ a consacrés à la religion, deux observations s'imposent, valables au demeurant pour la totalité de ses écrits. D'abord, un souci de grande précision, très encadré par la distinction entre d'une part ce qu'il a constaté lui-même, et d'autre part ce qui lui a été rapporté. En second lieu, parti comme "mathématicien » avec des connaissances réduites de l'arabe, $\mathrm{CN}$ est parvenu sur place à une telle maîtrise de la langue, parlée et écrite, qu'il a pu s'entretenir couramment et lire des ouvrages en cette langue, et cela sur pratiquement tous les sujets, dont la religion.

À cet égard, les savants français, dont le célèbre Sylvestre de Sacy ${ }^{110}$, sauront exprimer leur estime pour la qualité du travail de $\mathrm{CN}$ en matière de descriptions et de dessins de constructions, de copies d'inscriptions (ses « copies d'inscriptions de persan ancien, d'élamitique et de babylonien ont fourni les bases pour le déchiffrement de l'écriture cunéiforme par Georg Friedrich Grotefend à Göttingen en $1802 »^{111}$ ), pour ses essais d'interprétation, ainsi que pour les relevés en langue arabe de toponymes et autres mots, avec leurs variantes et les diverses manières de les écrire.

On ne peut qu'admirer le devenir d'un homme qui, parti pour effectuer des observations de tous ordres, mais toujours avec des résultats chiffrés, a su s'élever au point de rapporter une véritable somme dans des domaines qui n'étaient pas les siens (ethnologie, économie, religion, art, linguistique), somme qu'il publiera dans un délai rapide en s'appuyant sur de nombreux ouvrages connexes parus en diverses langues (allemand bien sûr, anglais, français, italien, latin, grec). Bien que ses brillants résultats dans les domaines qui étaient les siens, topographie, cartographie, astronomie, aient été largement ignorés de ses contemporains ${ }^{112}$, à deux exceptions près ${ }^{113}$, il faut

110. Les deux hommes ont correspondu et, dans ses mémoires à l'Académie, Sacy nomme CN une fois «l'illustre voyageur danois », une autre fois «cet estimable voyageur» (cf. notre art., op. cit., 7).

111. Wiesehöfer/Conermann, op. cit., 400.

112. En fait, le nom de $\mathrm{CN}$ n'aurait pas dû rester ignoré : il avait adressé les observations faites au cours de la traversée Copenhague-Marseille à T. Mayer, son maître à Göttingen, et ce dernier les avait trouvées si exactes qu'il les adressa immédiatement à Londres avec ordre de les publier à l'astronome anglais chargé de la nouvelle édition des tables du soleil et de la lune de Mayer. Myrkeline ne publia le livre qu'en 1770, avec en annexe X les mesures de CN sous le nom de ce dernier mais sans commentaires, et cela ne fut pas remarqué.

113. Il s'agit des deux « correspondants étrangers de la section d'astronomie de l'Académie des sciences » évoqués par le baron Dacier dans son éloge funèbre de CN le 17 juillet 1815 (Hist. de l'Académie Royale des Inscriptions et Belles-Lettres, vol. 7, Paris 1824, 160-174) ; cf. notre art., op. cit., 6. 
reconnaître à l'Institut national, prédécesseur de l'Institut de France, le mérite d'avoir conféré à $\mathrm{CN}$ la plus haute distinction dont pouvait bénéficier un savant étranger ${ }^{114}$ en se l'adjoignant le 25 mai 1802 comme associé étranger de la classe des sciences morales et politiques ${ }^{115}$.

Plus largement, constatation faite de l'absence (évoquée ci-dessus) de référence à Carsten Niebuhr chez des auteurs contemporains ${ }^{116}$, la présente publication pourrait être l'occasion de rendre à ce savant la place éminente que ses travaux méritent toujours.

41, rue Clisson

F 75013 Paris

midetalle@orange.fr

114. B. G. Niebuhr, qui évoque ce qu'il appelle une sorte de Nationalantipathie de son père envers notre pays (pour des raisons politiques, en particulier les épisodes sanglants de notre Révolution et les désastres engendrés un peu partout par les campagnes napoléoniennes), indique que son père reconnaissait cependant qu' «aucune société savante n'était comparable à l'Institut national en dignité et en éclat » (op. cit., 68, note 2 ).

115. Qui accueillait alors les « voyageurs » et les géographes ; sur ce point, cf. notre art., op. cit., 10.

116. $C f$. note 9 ci-dessus. 